证

1

\title{
Occurrence and predictive utility of isochronal, equiproportional, and other types of development among arthropods
}

Running Head: Proportionality in arthropod development

Department of Biological Sciences, University of New Brunswick, 100 Tucker Park Road, Saint John, NB, Canada E2L 4L5

*Corresponding author: bk.quinn@unb.ca, 1-506-343-7676

- Whether arthropod development is generally isochronal or equiproportional was tested

- Developmental proportions of most species' stages varied with temperature

- Many species had 'mixed' development between variable and equiproportional types

- The general occurrence of isochronal and equiproportional development was rejected

- Equiproportional development did make reasonable predictions of stage durations 


\section{ABSTRACT}

In isochronal (ICD) and equiproportional development (EPD), the proportion of total immature

27 (egg, larval, and/or juvenile) development spent in each stage (developmental proportion) does not vary among stages or temperatures, respectively. ICD and EPD have mainly been reported in copepods, and whether they occur in other arthropods is not known. If they did, then rearing studies could be simplified because the durations of later developmental stages could be predicted based on those of earlier ones. The goal of this study was to test whether different taxa have ICD, EPD, or an alternative development type in which stage-specific proportions depend on temperature, termed 'variable proportional' development (VPD), and also how well each development type allowed later-stage durations to be predicted from earlier ones. Data for 71 arthropods (arachnids, copepod and decapod crustaceans, and insects) were tested, and most $(85.9 \%)$ species were concluded to have VPD, meaning that ICD and EPD do not occur generally. However, EPD predicted later-stage durations comparably well to VPD (within 19$23 \%$ ), and thus may still be useful. Interestingly, some species showed a 'mixed' form of development, where some stages' developmental proportions varied with temperature while

42 Keywords: Equiproportional development; isochronal development; arthropod; larvae;

43 immature stages; temperature-dependent development 


\section{Introduction}

\subsection{Importance of studying immature arthropod development}

50

The immature phases of arthropod life cycles (i.e. eggs, larvae, and juveniles) are extremely important because they mediate recruitment to all later life stages (i.e. sexually mature adults). Survival through early life stages, growth rates of individuals to reproductive maturity or legal size for fisheries, inter-population connectivity, and seasonal patterns of abundance are all impacted by the length of time required to complete the immature phases (Huntley and López, 1992; Miller et al., 1998; Anger, 2001; Easterbrook et al., 2003; Reitzel et al., 2004; Pineda and Reyns, 2018). Development time of arthropods is strongly impacted by environmental temperature, with warmer conditions generally resulting in shorter development times within a species' tolerance limits (Nietschke et al., 2007; Shi et al., 2012; Rebaudo and Rabhi, 2018). There is therefore much interest and need to quantify the relationships between temperature and development time of immature arthropod life stages. Once such relationships have been determined for a given species, they can then be used to derive functions that are incorporated into models of larval dispersal, life history, production, etc. so that predictions of species' ecology and population dynamics can be made and tested against nature (Miller et al., 1998; Reitzel et al., 2004; Quinn et al., 2013). These efforts can inform fields such as fisheries ecology, food web modeling, predicting the spread of invasive species, pest management for agriculture, food science, epidemiology, forensic science, and so on (Huntley and López, 1992; Easterbrook et al., 2003; Lefebvre and Pasquerault, 2004; de Rivera et al., 2007; Yamamoto et al., 2014; Quinn, 2017). 
The usual approach used to quantify temperature-dependent development relations for

71 immature arthropods is to rear eggs, larvae, and/or juveniles at several different constant

72 temperatures in a laboratory setting, observe the time required to complete the immature phase(s)

73 at each temperature, and then derive a generalized equation(s) based on these observations to

74 predict development time at any temperature in nature (e.g., Anger, 1983, 1984, 1991, 2001;

75 MacKenzie, 1988; Easterbrook et al., 2003; Leandro et al., 2006a, b; Ouellet and Chabot, 2005;

76 Quinn et al., 2013). While simple in principle, many issues complicate this approach. One

77 particularly large challenge is the fact that most arthropod life history phases consist of multiple

78 immature stages, each separated by a moult and differing in morphology, physiology, and

79 behaviour (Anger, 2001; Li, 2002; Jacas et al., 2008; Jafari et al., 2012; Martin et al., 2014). For

80 the majority of species, the duration of each stage differs from that of the others, with later stages

81 tending to be longer than earlier ones (Corkett, 1984; MacKenzie, 1988), but not always. In

82 species with this type of development, the duration of each stage must usually be observed at

83 each temperature to model development accurately. This is problematic because it requires costly

84 maintenance of culture conditions and checking on experimental animals for extended time

85 periods. Importantly, this approach also often results in uncertain estimates of later stages'

86 durations due to small sample sizes following larval mortality in laboratory conditions (e.g., Ford

87 et al., 1979; Klein Breteler 1980; Quinn et al., 2013; Quinn, 2017). An approach that might allow

88 for reduced rearing costs and efforts and provide larger sample sizes for quantification of late-

89 stage durations would thus be useful. 
Two developmental concepts developed through observations on larval development of

94

copepod crustaceans seem to provide such potential shortcuts. These are the concepts of isochronal development (ICD) and equiproportional development (EPD) (Hart 1990, 1998;

Petersen, 2001). In a species with ICD, the durations of all developmental stages, and thus the proportion of total development spent in each stage, are identical (i.e. the ratios the of durations of all different stages or phases to one another is 1.0) (Miller et al., 1977; Corkett, 1984; Fig. 1A). In a species with EPD, the proportion of total immature development time spent in each larval phase and stage (i.e. the ratios of the durations of different stages or phases to one another) is constant within a species (Corkett and McLaren, 1970; Corkett, 1984; Fig. 1B), and perhaps even within larger taxonomic divisions (e.g., interspecific equiproportionality (ISE) within a genus, or intergeneric equiproportionality (IGE) within a family, sensu Hart, 1990). Importantly, within a species with ICD or EPD the proportion of total development spent in each stage or phase is independent of rearing temperature, and thus these proportions will be constant even if different temperatures lengthen or shorten the duration of each stage, phase, and total developmental duration (Corkett, 1984; Hart, 1990, 1998); this concept is illustrated in Fig. 1A, B, E, and F. ICD and EPD have historically been viewed as species-specific traits (Hart, 1994; Kiørboe and Sabatini, 1994; Petersen, 2001), such that some species have one of these types of development, while others have neither (Peterson and Painting, 1990; Carlotti and Nival, 1991) meaning that proportions of total development time varies among stages or phases and temperatures (Hart, 1998; Fig. 1C, D, G, H).

Initial studies rearing all immature stages of a species at multiple temperatures would be needed to confirm whether a given species of interest has ICD or EPD. Once these had been done, however, subsequent studies attempting to expand on different aspects of its temperature- 
dependent development [e.g., rearing larvae from different source populations to test for local adaptation (Leandro et al., 2006a; de Rivera et al., 2007; Quinn et al., 2013), rearing at more extreme temperatures to assess thermal limits (Pakyari et al., 2011; Shi et al., 2012)] should be able to use these estimates and forgo the expensive rearing of later stages. In the extreme case, a species with ICD need only be reared through one immature stage at one temperature for the durations of all other stages at all other temperatures to be estimated (Fig. 1A, E), while for a species with EPD rearing all stages at one temperature could in principle provide enough information to predict the durations of all stages at other temperatures (Corkett and McLaren, 1970; Corkett, 1984; Hart, 1990; Fig. 1B, F). In practice, because low food quality [a frequent issue in larval culture (Leandro et al., 2016b)] or other stressors [e.g., low pH (Keppel et al., 2012; Quinn, 2016), extreme temperatures (Quinn, 2016, 2017)] can lead to altered stagespecific developmental proportions for a species with ICD or EPD (Hart, 1998), it would likely be safest to rear all stages at one temperature and at least one stage at several other temperatures, as recommended by Corkett (1984) (see also Fig. 1F). However, even this approach can minimize rearing costs and efforts. This could further allow the durations of later stages for individuals that die during rearing in earlier stages to be estimated, giving a larger sample size for the quantification of later-stage durations and capturing more of the natural variability therein. There are, however, important limits or uncertainties to using ICD and/or ICD in this way, specifically that: (1) it is not known whether non-copepod crustaceans or other arthropods have these kinds of development; (2) there is no unequivocal, agreed-upon technique with which to actually test for the occurrence of ICD or EPD versus alternative possible development modes (e.g., in which stage proportions vary with temperature); and (3) no previous study has quantified 
138

139

140

141

142

143

144

145

146

147

148

149

150

151

152

153

154

155

156

157 158

the predictive utility of using ICD or EPD proportions to forecast later-stage durations based on durations of early stages. The present study sought to investigate and remedy these shortcomings.

\subsection{History of the study of ICD and EPD}

The concepts of ICD and EPD were initially described and named by Corkett (1984)

based on observations of ICD in the copepods in the genus Acartia by Miller et al. (1977) and

EPD in the copepods Pseudocalanus minutus (KRØYER, 1845), Eurytemora affinis (POPPE, 1880) (as E. hirundoides), and Temora longicornis (MÜLLER O.F., 1785) by Corkett and

McLaren (1970). Since then, these concepts (especially EPD) have been used and developed in numerous subsequent studies on copepods. Various studies of copepod species have claimed to demonstrate ICD and EPD (Hart, 1990; Petersen, 2001; Supplementary File 1, Table S1). Aside from general rearing studies, EPD studies have also investigated numerous topics, including: taxonomic patterns in the occurrence of ICD and EPD (Hart, 1990); the implications of developmental proportions to phenology-mediated interspecific interactions among sympatric copepods species (Hart, 1994); differences between egg-carrying and free-spawning species (Kiørboe and Sabatini, 1994); dependence of developmental proportions on food quality but independence from food quantity (Hart, 1998); differences between marine and freshwater copepod studies (Petersen, 2001); and impacts of toxicants affecting the moulting cycle on EPD (e.g., copper and chromium: Gutiérrez et al, 2010a), but not if they did not impact moulting (e.g., lindane: Brown et al., 2003; fish kairomones: Gutiérrez et al., 2010b).

Based on the above, it is apparent that research using the concepts of ICD and EPD has been copepod-dominated; indeed, all 21 relevant studies found in a 1 December 2017 Web of 
Science (Clarivate Analytics, 2018) search for 'equiproportional development', and all relevant studies within the first ten pages of a Google Scholar (Google, 2018) search for the same term on the same date, were carried out on copepods (Supplementary File 1, Table S1). However, there is no particular reason that these types of immature development may not also occur among other crustacean taxa (e.g., Miller, 2008), or perhaps even in non-crustacean arthropods (i.e. insects and arachnids). A handful of studies on non-copepod arthropods have applied these concepts (inname or not) to their species' data. Two studies of American lobster (Homarus americanus H. MILNE EDWARDS, 1837; Crustacea: Decapoda: Astacidea) larval development concluded that this species has EPD at temperatures from 10-22 ${ }^{\circ} \mathrm{C}$ (MacKenzie, 1988; Quinn et al., 2013). There is preliminary evidence suggesting that the larval development of other decapod crustaceans, such as snow crab (Chionecetes opilio (O. FABRICIUS, 1788); Decapoda: Anomura) and northern shrimp (Pandalus borealis KRØYER, 1838; Decapoda: Caridea), is equiproportional (P. Ouellet and B. Sainte-Marie, Fisheries and Oceans Canada, pers. comm.). Miller (2008) even speculated that development of the Aesop shrimp (Pandalus montagui LEACH, 1814; Decapoda: Caridea) might be isochronal at $12-15^{\circ} \mathrm{C}$. One study of a noncrustacean arthropod that considered developmental proportions at different temperatures was done by Lefebvre and Pasquerault (2004) on the dump fly Ophyra aenescens (WIEDEMANN, 1830) (Insecta: Diptera). That study found that this species spent different percentages of its total immature development in each stage at different temperatures $\left(17-30^{\circ} \mathrm{C}\right)$, and thus did not have ICD or EPD. Other studies of non-copepods or non-crustaceans considering developmental proportions spent in different stages may exist, but are difficult to find because the ICD and EPD terminology is largely unknown outside of the copepod literature. Given the potential reductions in study effort and costs for rearing a species with ICD or EPD discussed above, however, it 
184 185

186

187

188

would be worthwhile to investigate whether and which other arthropod taxa show these kinds of development.

\subsection{Uncertainties regarding ICD and EPD: possible alternatives and predictive ability}

Before various arthropod species can be investigated to determine whether or not they have ICD or EPD, an objective test is needed that can confirm or reject either of these types of development, and/or provide evidence that they described development data for a given species better than an alternative type of development (e.g., in which proportions vary among stages and temperatures; Petersen and Painting, 1990; Fig. 1C, D, G, H). Most of the foundational studies on copepods that considered ICD and EPD did so in a very informal manner, for example by calculating copepodite:nauplius or egg:nauplius phase duration ratios at different temperatures and subjectively deciding whether these were similar across temperatures (Corkett and McLaren, 1970; Corkett, 1984) or even just calculating ratios across temperatures (e.g., Hart, 1990). Such methods are not appropriate to make unequivocal conclusions regarding the type of development a given species has (e.g., Peterson and Painting, 1990; Carlotti and Nival, 1991). Studies by MacKenzie (1988) and Quinn et al. (2013) attempted to 'test' for EPD using formal statistical techniques, accounting for inter-individual variability and testing across temperatures. MacKenzie (1988) compared proportions using a two-way analysis of variance (ANOVA) with rearing temperature (5 levels) and larval stage (4 levels) as interacting factors. Quinn et al. (2013) performed separate one-way ANOVAs for each larval stage, with temperature as a factor with 4 levels. Both of these approaches treat temperature, a continuous variable, as a categorical factor, which is technically incorrect. Quinn et al. (2013)'s approach, or a similar alternative 
207

208

209

210

211

212

213

214

215

216

217

218

219

220

221

222

223

224

225

226

227

228

229

approach performing separate regressions or correlations of temperature vs. proportion for each stage, does not allow for comparisons among larval stages and thus cannot test for ICD vs. EPD. An analysis of covariance (ANCOVA, either linear or nonlinear), with the continuous variable temperature as 'covariate' and larval stage as a categorical factor may be a better general approach, although the typical interpretation of an ANCOVA focuses on the categorical factor and ignores functional relationships between the covariate or covariate*factor interaction and dependent variable. An ANCOVA approach is thus not ideal since functional quantitative relationships between temperature and developmental characteristics of arthropods are often quite important (e.g., Shi et al. 2012; Quinn, 2017; Shi et al. 2017a, b, c; Rebaudo and Rabhi, 2018).

An optimal approach would be the use of multiple generalized linear models, each designed to represent a hypothesis of development type (ICD, EPD, other), with an informationtheoretic approach used to compare models and select the 'best' one for a given species dataset (Anderson 2008; Quinn 2017). This latter approach was adopted in the present study, as detailed in section 2 (Materials and methods). An important component of such a method is the development of an alternative model, in which developmental proportions vary with temperature, against which to compare ICD and EPD. Within the present study, this form of development was termed 'variable proportional development' and abbreviated 'VPD', and models representing it were developed based on previous research on arthropod development. A number of studies have investigated the 'rate isomorphy' hypothesis, which proposes that relative durations of particular developmental stages are constant across temperatures, and/or that lower developmental thresholds are constant among development stages, on various ectotherm taxa, including insects, mites, and bamboos (e.g., Jarošík, 2002, 2004; Shi et al., 2010; Sandhu et al., 2011; Kuang et al., 
2012; Lin et al., 2018). In these studies, development rates were proposed to increase linearly with temperature across a range of intermediate temperatures, but could potentially deviate from linearity at more extreme (low and high) temperatures approaching a species' or stage's thermal limits. When such studies compared lower developmental thresholds across stages and temperatures, differences among stages but not temperatures demonstrated potential patterns comparable to EPD across many taxa, although with some potential exceptions; for example, deviations of the temperature-development relationship for a given stage(s) from linearity could indicate non-EPD (i.e. VPD) conditions. In addition, many previous studies of arthropod development have used both linear and nonlinear models to fit development time or rate data (e.g., Angilletta, 2006; Quinn 2017; Shi et al. 2017a, b, c; Rebaudo and Rabhi, 2018). Therefore, in the present study alternative VPD models to ICD and EPD were used, in which the developmental proportion for each stage could vary among stages as in EPD, but also could vary for the same stage as a linear or nonlinear (quadratic) function of rearing temperature. If ICD, EPD, or VPD are widespread phenomena among arthropod immature development, researchers should still of course be wary of relying too heavily on estimates (e.g., Corkett and McLaren, 1970; Corkett, 1984; Hart, 1990; Fig. 1F) of larval development times based on these. Therefore, the predictive utility of such developmental characteristics to estimate actual immature durations should be assessed; specifically, can one make accurate predictions of later larval stage durations based developmental proportion and duration of earlier stages? No study has yet tested the usefulness of these concepts in this way.

In this study, I examined data from studies of temperature-dependent immature development in arthropods from various taxonomic groups (copepod and non-copepod crustaceans, arachnids, and insects). I developed a technique to test for ICD, EPD, or VPD for 
253 each species (Fig. 1A-D). The distribution of different development types and the performance

254 of models based on different development types to describe species' datasets across taxa were

255 determined. The ability of each development type's model to estimate later-stage durations based

256 on earlier stages was also assessed. This is a unique study that applies and objectively tests for

257 ICD, EPD, and alternative development types (VPD) of arthropods, including non-copepod

258 species. Results have implications to rearing studies of immature arthropod stages in

259 temperature-dependent development studies, and may also provide a first step towards obtaining

260 information useful for further ecological and evolutionary studies.

261

262

263

\section{Materials and methods}

264

\subsection{Sources and handling of data}

268 (2016) or whose data were reanalyzed in a recent meta-analysis by Quinn (2017) were examined.

269 Studies that presented development time or rate data for multiple immature developmental stages

270 of one or more arthropod species at different rearing temperatures, and in a way that allowed

271 data to be extracted for analyses, were used as data sources. After excluding studies not meeting

272 these criteria (e.g., those presenting only mean values, or only data for total development), 71

273 different species' datasets from 60 different studies were obtained. While the primary objective

274 of the present study was to test for ICD, EPD, or VPD in non-copepod arthropods, any copepod

275 studies that presented useful data were still included to allow them to be tested using the new 
276

277

278

279

280

281

282

283

284

285

286

287

288

289

290

291

292

293

294

295

296

297

298

methods developed herein. The datasets collected came from studies published between 1963 and 2014 that examined various marine, freshwater, and terrestrial arthropods belonging to the arthropod subphyla Chelicerata (all arachnids, consisting of 9 mites and 1 spider), Crustacea (9 copepods and 19 decapods), and Hexapoda (33 insects belonging to 6 different orders) (Supplementary File 1, Table S2), and with both direct (anamorphic) and indirect (metamorphic) development (Table 1).

Developmental stages of these arthropods included any immature (pre-adult) stages, such as eggs, larval stages of crustaceans (nauplii, coepodites, zoeae, and decapodids), larval instars of insects, prepupae, and pupae of holometabolous insects, and nymphs of arachnids and nonholometabolous insects (Table 1; Supplementary File 2). Importantly, not all studies distinguished the durations of different developmental stages or instars within particular developmental phases (Table 1), but for the purposes of the present study all reported developmental periods (phases, stages, and/or instars) were equated. A phase contains multiple stages and has distinctive differences in its gross morphology from other phases (e.g., egg vs. larva vs. pupa; nauplius vs. zoea vs. decapodid) (Martin et al., 2014), while each stage is more similar to each other stage, although with smaller changes between them, and usually an instar involves an increase in size with little to no change in morphology (Martin et al., 2014).

However, equating these periods was reasonable in light of historical research on ICD and EPD, in which not only stage-specific proportions but also phase length ratios (e.g., nauplius vs. copepodite) were considered (Corkett, 1984; Hart, 1990). Additionally, among insects and arachnids the term 'instar' has a more specific meaning than it does among crustaceans, involving morphological changes that may be comparable to shifts between crustacean larval stages (e.g., Huang et al., 2008; de Oliveira et al., 2009; Eliopoulous et al., 2010). Phases, stages, 
and instars are separated by a moult in most species, and thus the timing of transitions between them and their durations is likely under the control of similar processes (Anger, 2001; Martin et al., 2014; Quinn, 2016, 2017). Further, for each species, data on the full span of immature phases before sexual maturity was captured except that for some species the duration of the egg phase was not reported and durations of juvenile stages were not reported for decapod crustaceans, as is typical for this taxon (see Table 1). It is thus unlikely that any inconsistencies among phases, stages, and instars should have strongly affected the conclusions drawn in the present study. Raw data or means \pm error (standard deviation (SD), standard error (SE), etc.) of development time and sample sizes for each developmental stage (and for total development if presented) were extracted from tables or figures in published papers for each of these 71 species and used to generate datasets for analyses. Data were extracted from figures using ImageJ (Schneider et al., 2012). If total development times were not presented in published studies, these were calculated by summing the average duration of all developmental stages and using the error variability and sample size of the last developmental stage reported; this procedure was applied for ten $(14.1 \%)$ of the 71 species datasets.

For each species dataset, once development time data were extracted the duration of each developmental stage had to be converted into a proportion of total development time to test for ICD, EPD, etc. This was done by dividing the duration of each stage by the total duration of development extracted or calculated above. For several species, supernumerary ('extra') developmental stages occurred at some rearing temperatures, but not others (e.g., the zoea $\mathrm{V}$ stage of the coconut crab Birgus latro (LINNAEUS, 1767) occurred at temperatures $\leq 24.6^{\circ} \mathrm{C}$, but not at higher temperatures; Hamasaki et al. 2009); such 'extra' stages were not considered in analyses in the present study (see Supplementary File 2), although they were accounted for in the 
322 calculation of total development times (thus influencing the relative developmental proportions

323 of other 'normal' stages) if appropriate. Many studies also reported experimental treatments (e.g.,

324 rearing temperatures) or replicates at which some (usually later) stage durations or total

325 developmental duration could not be reported due to poor or zero survival. Such treatments at

326 which all developmental stages did not occur were also excluded from analyses (see

327 Supplementary File 2 for the data included from each study). All data tallying and initial 328 calculations were performed in Microsoft Excel 2013.

2.2. Testing each species' dataset for ICD, EPD, and VPD whether its development was best explained by an ICD or EPD model of development, or an

334 alternative type of VPD. These tests were carried out in R version 3.1.1 (R Core Team, 2014)

335 using a code by the author (provided in Supplementary File 2). Data fed into each test were 336 replicates of the proportions of total development made up by each developmental stage at

337 different rearing temperatures in a given study. Because the data were proportions, their square-

338 root was first taken and then arcsine-transformed to meet assumptions of parametric tests

339 (homogeneity of variances and normality of residuals) (Ahrens et al., 1990). Four generalized

340 linear models (GLMs), all run assuming a Gaussian (normal) distribution of residuals (i.e. default

341 settings), were then tested on the data using the glm function in R. (GLMs were used instead of

342 regular linear models $(\mathrm{lm})$ to allow them to be input to the cross validation module described

343 later in this section.) Each GLM was intended to represent a different alternative mode of

344 arthropod development (see Table 2, and also Fig. 1A-D). First, an intercept-only model was 
tested to represent ICD, since in a species with ICD all developmental stages would take up identical proportions of total development. Second, a model including only development stage as a categorical factor was used to represent EPD, since in a species with real EPD the proportions of different stages can vary from each other, but are not affected by extrinsic factors like temperature. Two further models of VPD were then tested that represented testable alternatives to ICD and EPD (see section 1.4; Fig. 1C, D), in which the developmental proportion for each stage could vary among stages as in EPD, but also could vary for the same stage as a function of rearing temperature. Both a linear and a nonlinear (quadratic) version of this development type were tested, and their GLMs included stage as a categorical factor and temperature as a continuous factor, as well as the interaction of stage $\times$ temperature; the quadratic form of VPD also included temperature ${ }^{2}$ and the interaction of stage $\times$ temperature $^{2}$ (Table 2; see also Supplementary File 2). Although many different nonlinear function types exist that could be applied to arthropod development data (e.g., Quinn, 2017) and thus represent VPD, many of these require larger sample sizes and coverage of broader temperature ranges than those used in many of the studies examined (see Supplementary File2; also Quinn, 2017) to produce reasonable parameter estimates and fit. Therefore, in the present study a quadratic form of the nonlinear VPD model was used, as the quadratic development function is relatively simple and able to achieve fair performance on most datasets (Quinn, 2017). model to assess and compare how well each represented the data tested compared to the others.

365 First, values of Akaike's Information Criterion (AIC) adjusted for realistic finite sample sizes

$366\left(\mathrm{AIC}_{\mathrm{C}}\right)$, which represented the amount of useful information in each model (Anderson, 2008),

367 were calculated using the AICc function in the AICcmodavg package in R (Mazerolle, 2016). 
The model with the lowest $\mathrm{AIC}_{\mathrm{C}}$ value of all those tested on a given dataset is the best model for those data. Models were thus ranked from 1 (best) to 4 (worst if there were no ties) based on their $\mathrm{AIC}_{\mathrm{C}}$ for each dataset. Second, once the best function for a dataset was determined according to $\mathrm{AIC}_{\mathrm{C}}$ then model $\Delta_{\mathrm{i}}$ values were calculated as the $\mathrm{AIC}_{\mathrm{C}}$ of a given model minus the $\mathrm{AIC}_{\mathrm{C}}$ of the best model (Anderson, 2008). The best model therefore has $\Delta_{\mathrm{i}}=0$, and the $\Delta_{\mathrm{i}}$ of other models gives an index of information lost by using them rather than the best model; in general, if $\Delta_{\mathrm{i}}<2$ a non-best model still may contain some useful information, while if $\Delta_{\mathrm{i}}>14$ it is highly unlikely to contain useful information (Anderson, 2008). Third, a pseudo- $\mathrm{R}^{2}$ value representing model fit to the data was calculated by obtaining null and residual deviance values from GLM summary output in R (Supplementary File 2), and then dividing the residual by the null deviance and subtracting this from one. It should be noted that following this approach the ICD (intercept-only) model always had pseudo- $\mathrm{R}^{2}=0$ because its residual deviance equals its null deviance; comparisons among pseudo- $\mathrm{R}^{2}$ values were thus made with caution. Finally, the cross-validation error $(\%)$ of each model was calculated to assess how well each model did at predicting data (Davison and Hinkley, 1997; Picard and Cook, 1984). Cross-validation error was determined for each GLM using the cv.glm function in the boot package in R (Canty and Ripley, 2016), carrying out leave-one-out cross-validation $(\mathrm{K}=1)$ using the average squared error function (i.e. default parameters) (Davison and Hinkley, 1997). Overall, for each model a lower (better) ranking based on $\mathrm{AIC}_{\mathrm{C}}$, lower $\Delta_{\mathrm{i}}$, higher pseudo- $\mathrm{R}^{2}$, and lower cross-validation error indicated that that model performed better on the test dataset than others.

For each study dataset, the best development model (ICD, EPD, or linear or quadratic VPD) selected by $\mathrm{AIC}_{\mathrm{C}}$ was concluded to represent its species' 'true' mode of development (i.e. the best estimate thereof), and other parameters gave indices of how well the best and other 
development models represented its data. If the best model was found to be one of the VPD

models, for instance, then a given species' development could be concluded to not be

proportions among stages and temperatures for each dataset, GLM summary outputs from R were consulted. Whether coefficients calculated by the GLM for each factor and each level of each factor (for stages) were statistically significant $(\mathrm{p} \leq 0.05)$ was examined (see Table 2 for model equations and Supplementary File 2 for R outputs). For the EPD and both VPD models, if any stage was significant this was concluded to represent a significant effect of stage on

399 developmental proportions, and thus a rejection of ICD. For the VPD models, if temperature, 400 temperature $^{2}$, or the interaction term of any stage with temperature and/or temperature ${ }^{2}$ was 401 significant, then proportions of one or more stage(s) significantly varied among temperatures, 402 rejecting both ICD and EPD. Results of the above inferences generally agreed with conclusions based on $\mathrm{AIC}_{\mathrm{C}}$ rankings and applying ANOVAs to model outputs (see Supplementary File 3, Table S3), but provided additional information of interest. Specifically, for many species' datasets some stages'

406 proportions significantly varied with temperature, but those of other stages did not significantly

407 interact with temperature. Such species were concluded to have a 'mixed' form of development 408 intermediate between EPD and VPD (discussed more in section 2.3). For each stage that varied 409 among temperatures in a species with mixed development, the number of that stage in the 410 developmental sequence as well as the proportion of development completed up to the end of 411 each stage (the number of that stage in the developmental sequence divided by the total number 412 of stages examined) was noted and examined later. These data were visually examined to see 413 whether there were any patterns among taxonomic groups or in relation to the position in 
414 development of particular stages, for instance whether stages occurring earlier or later in

415 development were more or less likely to have their proportions affected by temperature. Logistic

416 regressions were also conducted to determine whether the likelihood of the proportion of

417 development spent in a given stage being affected by temperature was related to either that

418 stages' number or the proportion of development completed up until the end of that stage.

\subsection{Overall distribution and performance of each development type}

433 in these ANOVAs were development model (4 levels) and arthropod subphylum (3 levels), and 
437 analyses (Ahrens et al., 1990). If an overall statistically significant difference $(\mathrm{p} \leq 0.05)$ was

438 found among models or subphyla, Tukey's Honestly Significant Difference (HSD) test was used

439 to perform post-hoc comparisons. These analyses were carried out to assess how well each

440 development model performed across datasets, and to determine whether there were meaningful

441 overall differences between the best models for each dataset and the alternative models.

\subsection{Comparison of model performance on copepods versus other taxa}

As the concepts of ICD and EPD were initially developed in studies of copepods and

446 have historically been thought to apply well to development of these crustaceans (Corkett, 1984;

447 Hart, 1990, 1994, 1998; Petersen, 2001), it is feasible that these models might perform better on

448 data for copepod crustaceans than they do on data for other arthropods. Therefore, an additional

449 set of two-way ANOVAs on the four performance metrics described above $\left(\mathrm{AIC}\right.$ C rank, $\Delta_{\mathrm{i}}$,

450 pseudo- $\mathrm{R}^{2}$, and cross-validation error) was carried out, but this time the factors tested were

451 development model (4 levels, as before) and 'copepod' status (2 levels), meaning whether a

452 given species was a copepod or not. Tukey’s HSD test was used to perform post-hoc

453 comparisons among models if there were significant differences among these. 
460

461

462

463

464

465

466

467

468

469

470

471

472

473

474

475

476

477

478

479

480

481

482

studies assessing immature development in a particular species. In the extreme case, one could for example only rear the first developmental stage under particular experimental conditions, and use knowledge of ICD, EPD, etc. and known proportions to estimate the durations of all later developmental stages based on that of the first one (e.g., Fig. 1F). The effectiveness of this method of extrapolation was examined in the present study by calculating prediction errors for each of the four development model types considered. For each dataset and each model, actual durations of the earliest examined developmental stage and proportions for all subsequent development stages based on each model were used to estimate the duration of each later stage. For example, if stage 1 duration was 10 days and based on the EPD model stage 1 takes up 0.4 of total development time while stage 2 takes up 0.6, then stage 2 duration could be estimated as $10 *(0.6 / 0.4)$, or 15 days. For VPD models, variation in developmental proportions for each stage among rearing temperatures was also accounted for in these calculations.

Predicted durations were then compared to actual reported durations to estimate prediction error. To make values comparable across species with disparate developmental durations, and because no directionality was expected in terms of prediction errors, prediction error was calculated as an absolute percentage value by subtracting predicted from observed duration, dividing by observed duration, multiplying by $100 \%$, and taking the absolute value.

For each study dataset the average prediction error of each development model was averaged across all stages and replicates, and this average value was then used in subsequent overall analyses. The magnitude of overall prediction error for each model across datasets was examined. The minimum prediction error value from which the overall distribution of prediction errors of each model was not significantly different was determined through a series of one-sample $t$-tests, in which the data were compared to test values of first $0 \%$, and then gradually increasing percent 
483

484

485

486

487

488

489

490

491

492

493

494

495

496

497

498

499

500

501

502

503

504

505

error values (at $1 \%$ increments) until a p-value $\geq 0.05$ was attained. Whether mean prediction errors varied among development models or arthropod subphyla across datasets was also tested with a two-way ANOVA, using Tukey's HSD test for post-hoc comparisons among levels of any significant factor(s). Whether prediction errors of the four models differed overall between copepods and all other taxa examined was also tested with another two-way ANOVA with copepod status as one factor (2 levels) and model (4 levels) as the other, as described previously. These analyses tested the overall ability of these four proportional development models to predict later stage durations based on those of the earliest one. Also, since the ICD and EPD models were not found to best represent the majority of datasets tested (see Results, section 3) these tests allowed the ability of these simpler models to make predictions relative to the better but more complex ones to be tested, as well as whether the simpler models performed better on copepod data than on data for other arthropods.

\section{Results}

\subsection{Distribution of development types among arthropods}

Of the 71 arthropod species' datasets examined, the development of only $9(12.7 \%)$ were best represented by an EPD model (Fig. 2). These included one arachnid [Steneotarsonemus pallidus (BANKS, 1901) data from Easterbrook et al. (2003)], five insects [Anthonomus rubi HERBST, 1795 and Lygus rugulipennis POPPIUS, 1911 data from Easterbrook et al. (2003), Pseudococcus cryptus HEMPEL, 1918 data from Kim et al. (2008), and Frankliniella occidentalis (PERGANDE, 1895) data from Nondillo et al. (2008)], and four crustaceans, all of 
506

507

508

509

510

511

512

513

514

515

516

517

518

519

520

521

522

523

524

525

526

527

528

which were calanoid copepods [Eurytemora affinis, Pseudocalanus minutus, and Temora longicornis data from Corkett and McLaren (1970) and Pseudocalanus elongatus (BOECK, 1865) data from Klein Breteler et al. (1995)]. Only one species dataset (1.4\%) was best represented by an ICD model of development (Fig. 2), specifically the dataset from Ouellet and Chabot (2005) for the northern shrimp, Pandalus borealis, a decapod crustacean.

Development of the remaining 61 species (see Supplementary File 3, Table S3) was best described by a 'VPD' model of development of either a linear (10 species $=14.1 \%$ of datasets $)$ or nonlinear quadratic ( 51 species $=71.8 \%$ of datasets $)$ form (Fig. 2$)$. Of these 61 species for which either 'VPD' model was best, 18 represented cases of 'total VPD', in which the proportion of total development time taken up by all developmental stages varied significantly with temperature (Fig. 2). The remaining 43 species showed a 'mixed' form of development, in which the proportion of development taken up by one or more developmental stages significantly varied with temperature (representing stages with VPD), but proportions for one or more additional stages did not differ as a result of temperature (representing stages with EPD) (Fig. 2).

Overall 5 crustaceans (all non-copepods), 1 arachnid, and 12 insects had total VPD, while 18 crustaceans (including 5 copepods), 8 arachnids, and 17 insects had mixed development.

Among species with mixed development, there was a tendency for more stages with relatively low numbers in the developmental sequence (1-4) to have their proportions significantly affected by temperature (Fig. 3A), but this was due to there being few species among those examined with more than 4 stages in their immature development (see Supplementary Files 2 and 3, Tables S3 and S4). When stage number was divided by the total number of stages for each species, this pattern disappeared and there were no obvious points in development when significant temperature effects were more prevalent (Fig. 3B). A possible 
529

530

531

532

533

534

535

536

537

538

539

540

541

542

543

544

545

546

547

548

549

550

551

exception to this result was the last developmental stage, for which 25 of the 43 species with mixed development $(58.1 \%)$ showed temperature effects on developmental proportions (Fig. 3B; see also Supplementary File 3, Table S4). However, the likelihood of the developmental proportion for a stage in a species with mixed development being affected by temperature was not significantly related to stage number (logistic regression pseudo- $\mathrm{R}^{2}=0.001$, stage number $\mathrm{p}$ $=0.606$; Fig. $3 \mathrm{~A}$ ) or the proportion of development elapsed by the end of the stage (logistic regression pseudo- $\mathrm{R}^{2}=0.001$, development at stage $\mathrm{p}=0.614$; Fig. $3 \mathrm{~B}$ ). There were also no apparent differences among arthropod groups (Fig. 3A, B).

\subsection{Performance of different models of arthropod development}

\subsubsection{Overall model performance}

There were significant differences among the four models of arthropod development tested in terms of their ranking (out of four) based on $\mathrm{AIC}_{\mathrm{C}}$-values $\left(\mathrm{F}_{3,272}=144.392, \mathrm{p}<0.001\right.$; Fig. 4A), model $\Delta_{i}\left(F_{3,272}=11.499, p<0.001\right.$; Fig. 4B $)$, pseudo- $R^{2}$ values $\left(F_{3,272}=142.392, p\right.$ $<0.001$; Fig. 4C), and cross-validation error $\left(\mathrm{F}_{3,272}=23.102, \mathrm{p}<0.001\right.$; Fig. 4D). There were no significant differences among arthropod subphyla (arachnids, crustaceans, and insects) in the performance of any of these functions assessed based on model ranking (Subphylum $\mathrm{F}_{2,272}<$ 0.001, $\mathrm{p}>0.999$, Subphylum $\times$ Model interaction $\left.\mathrm{F}_{6,272}=0.848, \mathrm{p}=0.534\right), \Delta_{\mathrm{i}}\left(\right.$ Subphylum $\mathrm{F}_{2}$, $272=2.481, p=0.086$, Subphylum $\times$ Model interaction $F_{6,272}=1.705, p=0.120$ ), or pseudo- $R^{2}$ values $\left(\right.$ Subphylum $F_{2,272}=2.334, p=0.099$, Subphylum $\times$ Model interaction $F_{6,272}=0.339, p=$ 0.916) (Fig. 4A-C). Cross-validation error did significantly vary among subphyla $\left(\mathrm{F}_{2,272}=\right.$ $10.835, \mathrm{p}<0.001)$, although there was no significant interaction between subphylum and model 
$552\left(\mathrm{~F}_{6,272}=0.845, \mathrm{p}=0.536\right)($ Fig. 4D). This difference resulted because the cross-validation error

553 of all models for crustaceans was significantly lower than that for insects (Tukey's HSD test, $\mathrm{p}<$

554 0.001; Fig. 4D), likely due to the better performance of most models on data for copepods

555 (which are crustaceans) than non-copepods (see 3.2.2, Fig. 5). However, cross-validation error

556 for arachnids did not significantly differ from that for insects (Tukey's HSD test, $\mathrm{p}=0.051$ ) or

557 crustaceans (Tukey’s HSD test, $\mathrm{p}=0.650)($ Fig. 4D).

lowest (best) rank overall achieved by the nonlinear quadratic form of the variable proportional

(VPD) model, followed by the linear form of the VPD model, then the equiproportional model of

ICD model was consistently the worst and drove the significance of differences among models,

567 ICD model from analyses resulted in non-significant differences among models in terms of all metrics except rank (results not shown).

\subsubsection{Comparison of performance between copepod and non-copepod species' data}

Differences in the performance of models assessed in terms of $\Delta_{\mathrm{i}}$, (Model: $\mathrm{F}_{3,276}=7.034$,

$572 \mathrm{p}<0.001 ;$ Model $\times$ Copepod: $\mathrm{F}_{3,276}=0.001, \mathrm{p}>0.999 ;$ Fig. 5B), pseudo-R ${ }^{2}$ values (Model: $\mathrm{F}_{3}$,

$573276=98.453, \mathrm{p}<0.001 ;$ Model $\times$ Copepod: $\mathrm{F}_{3,276}=1.295, \mathrm{p}=0.276 ;$ Fig. $\left.5 \mathrm{C}\right)$, and cross-

574 validation error (Model: $\mathrm{F}_{3,276}=24.603, \mathrm{p}<0.001 ;$ Model $\times$ Copepod: $\mathrm{F}_{3,276}=2.069, \mathrm{p}=0.105$; 
575

576

577

578

579

580

581

582

583

584

585

586

587

588

589

590

591

592

593

594

595

596

597

Fig. 5D) were consistent between copepod and non-copepod arthropod species. Model crossvalidation errors were significantly lower $\left(\mathrm{F}_{1,276}=4.089, \mathrm{p}=0.044\right.$; Fig. 5D $)$ and pseudo- $\mathrm{R}^{2}$ values were significantly higher $\left(\mathrm{F}_{1,276}=11.650, \mathrm{p}=0.001\right.$; Fig. $\left.5 \mathrm{C}\right)$ for copepods than noncopepod species. However, model $\Delta_{\mathrm{i}}$ did not differ significantly between copepods and noncopepods $\left(\mathrm{F}_{1,276}<0.001, \mathrm{p}=0.988\right.$; Fig. 5B). There was a significant interaction between the effects of model type and whether species were or were not copepods on model rankings $\left(\mathrm{F}_{3,276}\right.$ $=4.843, p=0.003 ;$ Fig. 5A). This interaction resulted because certain models were ranked better overall for copepod species data than they were for non-copepods, specifically the quadratic VPD (one-way ANOVA comparing copepods versus non-copepods for one model at a time: $\mathrm{F}_{1}$, $\left.{ }_{69}=4.137, \mathrm{p}=0.046\right)$ and EPD models $\left(\mathrm{F}_{1,69}=7.209, \mathrm{p}=0.009 ;\right.$ Fig. 5A), while rankings for the linear VPD $\left(\mathrm{F}_{1,69}=0.005, \mathrm{p}=0.944\right)$ and ICD models $\left(\mathrm{F}_{1,69}=0.331, \mathrm{p}=0.567\right)$ did not significantly differ between copepod and non-copepod species (Fig. 5A).

\subsection{Prediction error of development models}

Absolute percent prediction error differed significantly among models $\left(\mathrm{F}_{3,272}=31.144, \mathrm{p}<\right.$ 0.001), but not among subphyla (Subphylum: $F_{2,272}=0.237, p=0.789$; Model $\times$ Subphylum: $F_{6}$, $272=1.739, \mathrm{p}=0.112)($ Fig. 6A). Differences among models were driven by the fact that ICD (mean percent error $=77.8 \%$ ) had much and significantly (Tukey's HSD test, all $\mathrm{p}<0.001)$ greater error than all other models (mean errors $=25.0-28.4 \%)($ Fig. 6A). EPD and both forms of VPD did not have significantly different percent errors from each other (Tukey's HSD test, $p$ $\geq 0.948$ ) (Fig. 6A). If ICD was removed from consideration, there was no significant difference among models in terms of their prediction error (e.g., Model $\mathrm{F}_{2,204}=0.250, \mathrm{p}=0.772$; other 
598

599

600

601

602

603

604

605

606

607

608

609

610

611

612

613

614

615

616

617

618

619

620

results not shown). The prediction errors of the ICD, EPD, linear VPD, and quadratic VPD models were overall not significantly greater than $64,23,21$, and $19 \%$, respectively (one-sample $t$-tests, $\left.\mathrm{t}_{70} \leq 1.921, \mathrm{p} \geq 0.056\right)$. When comparing model predictive ability on copepod versus non-copepod species' datasets, percent errors also did not differ between copepods and noncopepod species (Copepod: $\mathrm{F}_{1,276}=1.212, \mathrm{p}=0.272$; Model $\times$ Copepod: $\mathrm{F}_{3,276}=0.141, \mathrm{p}=$ 0.936), only among models $\left(\mathrm{F}_{3,276}=16.558, \mathrm{p}<0.001\right)($ Fig. 6B).

\section{Discussion}

\subsection{Comparison of results to previous studies}

\section{In the present study, it was found that isochronal (ICD) and equiproportional} development (EPD) were not general phenomena among the arthropod species examined, as the development of the vast majority of species (61 out of 71 , or $85.9 \%$ ) was best represented by a variable proportional (VPD) model of development. In comparison with previous studies of some of the species examined in this one, the new analytical technique used led to different conclusions regarding whether they had ICD or EPD. The decapod crustaceans Chionoecetes opilio, Pandalus borealis, and Pandalus montagui were previously suspected to have EPD (C.

opilio and P. borealis: P. Ouellet and B. Sainte-Marie, Fisheries and Oceans Canada, pers. comm.) or ICD (P. montagui: Miller, 2008), but in this study C. opilio and P. montagui were concluded to have VPD, and P. borealis was the only species concluded to have ICD. Both MacKenzie (1988) and Quinn et al. (2013) concluded that the decapod Homarus americanus had 
621 EPD, but reanalyses of their data in the present study showed that this species has VPD, with the

622 proportions of development in all three zoeae and the decapodid stage (MacKenzie, 1988) or the

623 third zoea only (Quinn et al. 2013) varying with temperature in a quadratic manner

624 (Supplementary File 3, Tables S3 and S4). Results of this study did, however, confirm those

625 inferred from the different developmental proportions reported at different temperatures by

626 Lefebvre and Pasquerault (2004) for the insect Ophyra aenescens, as this species was found to

627 have VPD. Among the 9 copepods examined in the present study, the development of four

628 species (Eurytemora affinis, Pseudocalanus elongatus (data from Klein Breteler et al., 1995),

629 Pseudocalanus minutus, and Temora longicornis) previously thought to have EPD (Corkett and

630 McLaren, 1970; Hart, 1990; Kiørboe and Sabatini, 1994; Petersen, 2001) were concluded to be

631 best represented as EPD. However, the remaining five copepod species' datasets were all

632 concluded to be best represented by the VPD models, and three of these species were concluded

633 by previous studies (Miller et al., 1977; Geiling and Campbell, 1992; Hart, 1990; Kiørboe and

634 Sabatini, 1994; Petersen, 2001) to have EPD [Skistodiaptomus pallidus (HERRICK, 1879) data

635 from Kamps (1978), and Pseudocalanus elongatus data from Thompson (1982)] or ICD [Acartia

636 (Acanthacartia) tonsa DANA, 1849 data from Leandro et al. (2006b)]) (see Supplementary File

637 1, Table S1). Therefore, while EPD did seem to represent data for copepod species somewhat

638 better than that of other crustacean and arthropod taxa, the general occurrence of EPD among

639 copepod crustaceans noted in previous studies was not confirmed.

640 The different conclusions from previous studies described above were presumably due to

641 the use of an improved method to test for EPD in this study, as previous studies either did not

642 perform formal statistical tests for ICD or EPD, or if they did, they mostly did not also test and

643 compare alternative models (e.g., VPD). The differences in conclusions for some datasets for the 
644

645

646

647

648

649

650

651

652

653

654

655

656

657

658

659

660

661

662

663

664

665

666

same species but obtained from different studies [H. americanus: total VPD (MacKenzie, 1988)

vs. mixed VPD (Quinn et al., 2013); P. elongatus: EPD (Klein Breteler et al., 1995) vs. VPD

(Thompson, 1982)] were interesting outcomes. It is noteworthy that in each of these pairs of

studies, the one for which the least variable form of development was concluded as best was also

the one with the smaller sample size of the two (Supplementary File 2). The ten species for

which ICD or EPD were concluded to be a better representation of their development than VPD

also tended to have relatively small sample sizes for each stage and temperature compared to all

the other datasets examined (see Supplementary File 2). Therefore, it is very likely that the

conclusion of EPD in these cases does not represent an actual biological characteristic of these

species, but simply insufficient power to detect their VPD due to low replication. Indeed, if

sample sizes are small but the models fit to the data become more complex, as in the case of

VPD (especially the quadratic form of the model), the bias introduced by greater model

complexity (i.e. more parameters) outweighs the improved fit achieved by the model, and thus

lowers its information content, increases its $\mathrm{AIC}_{\mathrm{C}}$ value, and worsens its rank (Anderson, 2008;

Quinn, 2017). It would thus be reasonable to expect an analysis of data from a better-replicated

study of the species for which ICD and EPD were concluded in this study to result in them being

found to actually have VPD.

\subsection{The reality of ICD and EPD and implications of plastic and mixed development}

The occurrence of ICD and EPD in the immature development of arthropods, including among the copepod species for which they were first reported, is thus unlikely to be a 'real' phenomenon in nature. This finding is perhaps not so surprising, given that an increasing body of 
667

668

669

670

671

672

673

674

675

676

677

678

679

680

681

682

683

684

685

686

687

688

689

work in recent years has shown that many (and possibly all?) arthropod species exhibit at least some plasticity in their immature developmental pathways (Jarošík et al., 2002, 2004; Oliphant et al., 2013; Karimi-Malati et al., 2014; Quinn, 2016). Many species of decapod crustaceans (e.g., Boyd and Johnson, 1963; Hamasaki et al., 2009) and insects (e.g., Karimi-Malati et al., 2014) develop through additional or alternative stages or instars under suboptimal conditions, such as extreme temperatures, low food supply, presence of contaminants, or limited availability of substrate for settlement (Oliphant et al., 2013; Quinn, 2016 and references therein). In many cases, such developmental plasticity is thought to be adaptive; for example, at low temperatures the shrimp Palaemon varians LEACH, 1813 (formerly Palaemonetes varians) develops through 1-3 additional stages at lower temperatures than it does at higher temperatures, which is presumed to allow it to delay settlement to juvenile habitats and give it more time to feed and grow to a larger size before settling (resulting in lower post-settlement mortality) than it otherwise could achieve under low-temperature conditions (Oliphant et al., 2013). In many of the species examined herein and found to have VPD, additional developmental stages did occur at some temperatures (see original studies cited in Supplementary File 1, Tables S2), resulting in immediately altered proportions for all 'normal' stages at these temperatures. However, for many others with VPD extra stages did not occur, but instead the specific allocation of the developmental period to each stage changed among temperatures (e.g., Campolo et al., 2004). The specific implications of this form of plasticity are not immediately clear and likely vary on a case-by-case basis, but one can imagine similar outcomes to the occurrence of extra stages. For instance, the lengthening of the last developmental stage at suboptimal temperatures may permit more feeding in preparation for metamorphosis, and thus attaining a larger postmetamorphic size (sensu Oliphant et al., 2013). The results of the present study strongly suggest that 
690

691

692

693

694

695

696

697

698

699

700

701

702

703

704

705

706

707

708

709

710

711

characteristics of arthropod species. arthropod taxa (Quinn, 2016).

developmental plasticity is a general phenomenon among arthropods, but more research is needed on the exact nature, evolution, and implications of developmental plasticity among

The observation of a 'mixed' type of development between EPD and VPD in many species in the present study was an unexpected finding, which suggests that even within the same species the proportion of development spent in different stages may be differently affected (or not) by temperature. No obvious overall relationship between where in the developmental sequence a stage fell and the likelihood of its proportion being affected by temperature was found, so the reasons for the temperature (in)dependence of each species' stages' developmental proportions must be investigated individually in a future analysis. One can imagine that some stages likely have greater scope for developmental plasticity than others. For example in a species with both feeding and non-feeding stages, one would expect the non-feeding stages to have less plasticity due to their lifetime being limited by stored reserves (Jirkowski et al., 2015; Pineda and Reyns, 2018). Perhaps some intermediately timed stages might also be less flexible if processes occur during them that are required for later development and successful metamorphosis, as in the second zoea stage of many decapods (Anger 2001; Quinn, 2016). Later stages of crustaceans, which must settle to the benthos before metamorphosing, may also be more plastic due to the possibility of them not encountering suitable substrate immediately when reaching competence (Pineda and Reyns, 2018) or having experienced insufficient growth as larvae to be successful after metamorphosis (Oliphant et al., 2013). Future analyses of such possible features of mixed and VPD types of development will no doubt reveal interesting 

stages' durations than did EPD, and especially ICD, so it does represent an improvement over these simpler models that should be used more in future studies. However, an important finding

718 of this study was that although EPD was rarely the best descriptor of any species' immature development, it did perform comparably well to the VPD models on most species' datasets and had similar predictive ability to these 'better' models. The mean pseudo- $\mathrm{R}^{2}$ values of the EPD

721 model were always within 1-8 \% of those of the VPD models (depending on subphylum), and error of the EPD model was also within 1-4 \% of that of the two VPD models, and all three of these models had overall prediction errors significantly less than or equal to 19-23\%. Therefore, 725 although EPD is likely not 'real' and is not the best representation of most species' immature development, for most practical purposes it may be appropriate to use it as a fair approximation

728 would require a lot of time and resources, whereas the data required to model EPD and make 729 predictions of later stages' durations based on it is potentially much less (see Fig. 1B, F in

730 section 1; Corkett, 1984; Hart, 1990). Caution should still be taken before applying EPD too 731 broadly, however, as the actual nature of arthropod development is plastic (VPD), and in some

732 cases (e.g., occurrence of extra larval stages and/or plasticity near extreme temperatures;

733 Oliphant et al., 2013; Karimi-Malati et al., 2014) the developmental alterations that result from 734 this plasticity can have major impacts on the ecology of immature stages (Oliphant et al., 2013; 735 Quinn, 2016). Therefore, the decision of whether predictions made using EPD are accurate 
736

737

738

739

740

741

742

743

744

745

746

747

748

749

750

751

752

753

754

755

756

757

758

enough must lie with each individual study, and be based on its objectives and the sensitivity of these outcomes to the developmental plasticity of the species involved.

\subsection{Limitations and perspectives for future work}

There are of course some important limitations to the results of the present study. While

the number of species' datasets examined (71) was fairly large and included members of all three major arthropod subphyla, these only provided information for species from a limited sample of the diverse taxa within these subphyla, including only two crustacean classes, very few copepod species, and only 10 chelicerates (all arachnids, all but one of which were mites). These datasets were also obtained in a non-random and semi-arbitrary manner from studies examined in previous reviews (Quinn, 2016, 2017), although it should be noted that Quinn (2017) did perform a standardized search of the temperature-dependent arthropod development literature to obtain their study datasets. For a small percentage of datasets $(14.1 \%)$, total developmental durations were not reported in original studies and thus had to be indirectly calculated, which may have introduced some errors (though probably small ones) into the calculation of developmental proportions. While a more extensive survey of the literature encompassing more arthropod species and taxa would certainly provide stronger conclusions (and should certainly be done, see below), there was no reason to suspect any particular biases in the results obtained herein affecting the main conclusions. Further, the fact that similar trends, such as VPD being far more prevalent than ICD or EPD, were found for members of all three subphyla examined lends some support to the generality and representativeness of the conclusions drawn. 
It is also important to note that the results for copepods herein strongly call in to question

760

761

762

763

764

765

766

767

768

769

770

771

772

773

774

775

776

777

778

779

780

781

the occurrence of ICD and EPD among these crustaceans, which is contrary to a great deal of

previous research (e.g., Hart, 1990, 1994, 1998; Petersen, 2001; but see Carlotti and Nival, 1991;

Petersen and Painting, 1990). However, to confirm this result more than nine species of

copepods need to be examined. If possible, a follow-up review should attempt to obtain more

high-quality data from the literature for many more copepod species, including for more of those that were previously concluded to have ICD or EPD, and test their data using the techniques developed in this study. Given the types of data (e.g., means only) based on which previous studies concluded ICD and EPD in copepods, however, extracting sufficient data from published papers to test with VPD models may not be possible; in this case, new experimental studies rearing copepods at different temperatures will be necessary to obtain the data needed to conclusively test whether ICD or EPD rather than VPD occur among these species.

Perhaps a more significant limitation was that a wide variety of developmental increments were equated under the common term 'developmental stages' in the present study (Table 1). There are important distinctions between developmental phases, stages, and instars, for example, which were ignored in this study, but as outlined earlier (see section 2.1) it is unlikely that these inconsistencies should have affected the conclusions of the present study.

However, a study accounting for phase-stage-instar differences in developmental proportions may be illuminating, and thus should be done in the future. The possibility that the type of development or scope for developmental plasticity might differ among arthropods with anamorphic as opposed to metamorphic development may also be worth investigating.

The statistical analyses performed in the present study were robust and novel, but they did also have limitations that could be improved in future work. For example, the linear and 
782 quadratic VPD models used are only two of a large number of different potential temperature-

783 dependent development function types (e.g., Quinn, 2017) that might be applied to such data,

784 and some more complex function types exist that can even capture underlying physiological

785 processes, such as enzyme thermoactivation and thermoinhibition, involved in thermal effects on

786 development (e.g., Schoolfield et al., 1981; Shi et al., 2017c). While such highly complex

787 functions could only be applied to datasets with relatively large sample sizes, it would certainly

788 be worth looking at developmental proportions using them in the future. It is also conceivable

789 that the developmental proportions of stages in some species may not exhibit an even, curvilinear

790 relationship with temperature, but might instead vary in a 'chaotic' or 'sporadic' manner among

791 temperatures. A reasonable model of 'sporadic' development could not be developed in the

792 present study, but it may be worth pursuing in the future. It is also well established that

793 development times of arthropods vary not only with temperature, but also as a function of other

794 environmental and biotic factors such as salinity, food quality or quantity, social interactions,

795 oxygen, pH, etc., and different combinations thereof (Anger, 1991; Klein Breteler, 1980; Klein

796 Breteler et al., 1995; Anger, 2001; Keppel et al., 2012); the possibility that developmental

797 proportions might vary due to such factors should also be investigated using an approach

798 analogous to the one developed for temperature in this study. It would also likely be very useful

799 to combined the datasets and approaches used in this study with some of those from the literature

800 on development rate isomorphy among ectotherms (Jarošík, 2002, 2004; Shi et al., 2010; Sandhu

801 et al., 2011; Kuang et al., 2012; Lin et al., 2018). Doing so could increase the taxonomic range

802 over which data were collected and analyzed, and allow for these two approaches to be combined

803 and analyzed in interesting and useful ways. 
Analyses in this study were also confined to the available data obtained from previous

805

806

807

808

809

810

811

812

813

814

815

816

817

818

819

820

821

822

823

824

825

826

studies, and thus all assessments of model performance and predictive ability were based on the

fit of development models to the data used to generate them. Therefore, a true test of the

performance and predictive ability of models of different types of development would need to be carried out on new data (Picard and Cook, 1984). For example, future studies should rear

immature stages of the species examined in this one, and compare the developmental proportions and durations of different stages at different temperatures to the stage- and temperature-specific developmental proportions for these species predicted by the different models (EPD, VPD, etc.) tested in this study. Only then could a definitive conclusion be reached regarding the occurrence or not of EPD and other development types among arthropods be reached. Of course, such studies should also test other factors impacting development times (salinity, etc. as described above), and likely also should be conducted over very wide thermal ranges to determine whether and how developmental proportionality breaks down near thermal extremes (Schoolfield et al., 1981; Shi et al., 2012; Quinn, 2017). Also, since such studies are most likely to be conducted in laboratory settings, at constant temperatures, caution should be taken in applying their results (and those of the present study) to predicting arthropod development in nature. Development in variable thermal regimes can differ from that at constant temperatures (Anger, 1983), and in field conditions development can occur more quickly or slowly (Anger, 2001; Niehaus et al., 2012) than in the laboratory, depending on the species.

A considerable amount of information on the proportions of development spent by arthropod species belonging to various taxa in different immature stages at different temperatures has been amassed during the present study (Supplementary File 3, Table S4). As already discussed, these data and the developmental proportions predicted by models of ICD, EPD, and 
827

828

829

830

831

832

833

834

835

836

837

838

839

840

841

842

843

844

845

846

847

848

849

VPD based on them could be used to predict development times in future studies on these species. These data also provide information useful for endeavours such as larval dispersal modeling (Reitzel et al., 2004; Quinn et al., 2013; Pineda and Reyns, 2018), predictions of pest dynamics (Easterbrook et al., 2003; Campolo et al., 2009; Eliopoulous et al., 2010), ecosystem models (Huntley and López, 1992), and so on. However, there is also much potential for this information on the developmental proportions and their dependence on temperature (or not) to be analyzed across species and higher taxa from an ecological or evolutionary perspective.

The proportion of development spent by a particular species in each developmental stage may reflect evolutionary adaptation to the phenology of conditions encountered in its habitat. For example, most decapod crustacean larval stages take up progressively longer portions of development (MacKenzie, 1988; Anger, 2001; see also the data in Supplementary Files 2 and 3). In decapod species in temperate regions, this means that early-stage larvae, which take up the smallest proportion of development at a particular temperature, experience the coldest conditions, while later-stage larvae that can take up larger developmental proportions experience the warmest conditions; this means that the shortest, earliest stages experience the greatest inhibition by cold, while the longest, later stages experience the greatest acceleration by warmth, which may optimize overall development time and effectively make development in nature isochronal.

As reported for copepods (Hart, 1994), the proportions for a particular species' stages might also be optimized to avoid temporal and spatial overlap with competing species in the same habitat. It is also conceivable that the degree of developmental plasticity exhibited by a species can be explained by its life habits. Species inhabiting environments with more variable temperature regimes than others, such as terrestrial species, might be expected to have more flexible development than those in less variable (e.g., aquatic) habitats (Shi et al., 2012; Quinn, 2017). 
850 There is thus the potential to compare the characteristics of one species' development with its

851 habitat to assess whether particular features of the habitat have selected for a particular form of

852 development.

While no obvious taxonomic patterns were detected in the present study, the information

854 collected might later be used on a larger scale to specifically answer broad evolutionary

855 questions. Heterochrony is the changing of the timing of events during development, and it is

856 associated with many major evolutionary transitions, including among arthropods (Jirkowsky et

857 al., 2015). A phylogenetic analysis of the proportion of development spent in different stages

858 among closely related species or higher taxa might reveal interesting evolutionary patterns. For

859 example, one could examine whether: the loss or gain of a larval stage is associated with changes

860 to the developmental proportions of other stages; greater plasticity is associated with species

861 shifting their ranges into more thermally variable environments; developmental proportions can

862 be used in addition to other phylogenetic characters to enhance taxonomical distinctions among

863 species; evolution towards direct development (loss of free-living larval stages) is preceded by

864 reductions in developmental proportions of larval stages; apparently similar larval stages, such as

865 the nauplii of dendrobranchiate and euphausiid crustaceans, are equivalent to those that are free-

866 living in other taxa or embryonized (reduced and completed in the egg) in others (Jirkowski et al.,

867 2015); and so on. While a more extensive database including many more species and higher taxa

868 is needed before such analyses can be conducted, the present study is a first step in this direction,

869 which should lead to many informative and interesting investigations in the future.

\section{Acknowledgements}


873 The University of New Brunswick, Saint John Campus, provided resources that made the review

874 and analyses in this paper possible. I thank Gerhard Scholtz and two anonymous reviewers for

875 comments that improved the manuscript. The author thanks Bernard Sainte-Marie, Patrick

876 Ouellet, Heather Major, Heather Hunt, Jeff Houlahan, Rémy Rochette, and members of the

877 Biology 6000 class feedback committee and Rochette-Hunt lab at UNBSJ for feedback and

878 guidance during this project. I thank Tammy Sha Bo in particular for observations that led to the

879 idea and models for VPD developed herein, which allowed for much more sensible and novel

880 tests of EPD versus alternatives; this work is dedicated to her.

881

882

\section{References}

883

884

Ahrens, W.H., Cox, D.J., Budhwar, G., 1990. Use of the arcsine and square root transformations for subjectively determined percentage data. Weed Sci. 38, 452-458.

Anderson, D.R., 2008. Model Based Inference in the Life Sciences: A Primer on Evidence.

Anger, K., 1983. Temperature and the larval development of Hyas araneus L. (Decapoda: 2013-215.

Anger, K., 1984. Development and growth in larval and juvenile Hyas coarctatus (Decapoda, Majidae) reared in the laboratory. Mar. Ecol. Prog. Ser. 19, 115-123.

893 Anger, K., 1991. Effects of temperature and salinity on the larval development of the Chinese mitten crab Eriocheir sinensis (Decapoda: Grapsidae). Mar. Ecol. Prog. Ser. 72, 103-110. 
Anger, K., 2001. Crustacean Issues 12: The Biology of Decapod Crustacean Larvae. A.A. Balkema, Rotterdam, The Netherlands.

Angilletta, M.J., Jr., 2006. Estimating and comparing thermal performance curves. J. Therm. Biol. 31, 541-545.

Boyd, C.M., Johnson, M.W., 1963. Variations in the larval stages of a decapod crustacean, Pleuronectes planipes (Galatheidae). Biol. Bull. 124, 141-152.

Brown, R.J., Rundle, S.D., Hutchinson, T.H., Williams, T.D., Jones, M.B., 2003. A copepod lifecycle test and growth model for interpreting the effects of lindane. Aquat. Toxicol. 63, 111.

Campolo, O., Malacrinò, A., Laudani, F., Maione, V., Zappalà, L., Palmeri, V., 2009. Population dynamics and temperature-dependent development of Chrysomphalus aonidum (L.) to aid sustainable pest management decisions. Neotrop. Entomol. 43, 453-464.

Canty, A., Ripley, B., 2016. boot: Bootstrap R (S-Plus) Functions. R Package Version 1.3-18. Available at: http://CRAN.R-project.org/package=boot.

Carlotti, F., Nival, S., 1991. Individual variability of development in laboratory-reared Temora stylifera copepodites: consequences for the population dynamics and interpretation in the scope of growth and development rules. J. Plankton Res. 13, 801-813.

Corkett, C.J., 1984. Observations on development in copepods. In: Crustaceana Supplement No. 7, Studies on Copepoda II (Proceedings of the First International Conference on Copepoda, Amsterdam, the Netherlands, 24-28 August 1981), pp. 150-153.

Corkett, C.J., McLaren, I.A., 1970. Relationships between development rate of eggs and older stages of copepods. J. Mar. Biol. Assoc. UK 50, 161-168. 
917

Davison, A.C., Hinkley, D.V., 1997. Bootstrap Methods and Their Applications. Cambridge University Press, Cambridge, UK.

Easterbrook, M.A., Fitzgerald, J.D., Pinch, C., Tooley, J., Xu, X.-M., 2003. Development time and fecundity of three important arthropod pests of strawberry in the United Kingdom. Ann. Appl. Biol. 143, 325-331.

Eliopoulous, P.A., Kontodimas, D.C., Stathas, G.J., 2010. Temperature-dependent development of Chilocorus bipustulatus (Coleoptera: Coccinellidae). Envrion. Entomol. 39, 1352-1358.

Ford, R.F., Felix, J.R., Johnson, R.L., Carlberg, J.M., Van Olster, J.C., 1979. Effects of fluctuating and constant temperatures and chemicals in thermal effluent on growth and survival of the American lobster (Homarus americanus). Proc. World Maricul. Soc. 10, $139-158$.

Geiling, W.T., Campbell, R.S., 1972. The effect of temperature on the development rate of the major life stages of Diaptomus pallidus Herrick. Limnol. Oceanogr. 17, 304-307.

Gutiérrez, M.F., Gagneten, A.M., Paggi, J.C., 2010a. Copper and chromium alter life cycle variables and the equiproportional development of the freshwater copepod Notodiaptomus conifer (SARS). Water Air Soil Poll. 213, 275-286.

Gutiérrez, M.F., Paggi, J.C., Gagneten, A.M., 2010b. Fish kairomones alter life cycle and growth of a calanoid copepod. J. Plankton Res. 32, 47-55.

Hamasaki, K., Sugizaki, M., Dan, S., Kitada, S., 2009. Effect of temperature on survival and developmental period of coconut crab (Birgus latro) reared in the laboratory. Aquaculture 292, 259-263. 
Hart, R.C., 1990. Copepod post-embryonic durations: pattern, conformity, and predictability. The realities of isochronal and equiproportional development, and trends in the copepodite-naupliar duration ratio. Hydrobiologia 206, 175-206.

Hart, R.C., 1994. Equiproportional temperature-duration responses and thermal influences on distribution and species switching in the copepods Metadiaptomus meridianus and Tropodiaptomus spectabilis. Hydrobiologia 272, 163-183.

Hart, R.C., 1998. Copepod equiproportional development: experimental confirmation of its independence of food supply level, and a conceptual model accounting for apparent exceptions. Hydrobiologia 380, 77-85.

Huang, Z., Ren, S., Musa, P.D., 2008. Effects of temperature on development, survival, longevity, and fecundity of the Bemisia tabaci Gennadius (Homoptera: Aleyrodidae) predator, Axinoscymnus cardilobus (Coleoptera: Coccinellidae). Biol. Control 46, 209215.

Huntley, M.E., López, M.D.G., 1992. Temperature-dependent production of marine copepods: a global synthesis. Am. Nat. 140, 201-242.

Jacas, J.A., Peña, J.E., Duncan, R.E., Ulmer, B.J., 2008. Thermal requirements of Fidiobia dominica (Hymenoptera: Platygastridae) and Haeckeliania sperata (Hymenoptera: Trichogrammatidae), two exotic egg parasitoids of Diaprepes abbreviatus (Coleoptera: Curculionidae). BioControl 53, 451-460.

Jafari, S., Fathipour, Y., Faraji, F., 2012. Temperature-dependent development of Neoseiulus barkeri (Acari: Phytoseiidae) on Tetranychus urticae (Acari: Tetranychidae) at seven constant temperatures. Insect Sci. 19, 220-228. 
960

961

962

963

964

965

966

967

968

969

970

971

972

973

974

975

976

977

978

979

980

981

Jarošík, V., Honěk, A., Dixon, A.F.G., 2002. Developmental rate isomorphy in insects and mites. Am. Nat. 160, 497-510.

Jarošík, V., Kratochvíl, L., Honěk, A., Dixon, A.F.G., 2004. A general rule for the dependence of developmental rate on temperature in ectothermic animals. Proc. R. Soc. B. 271, S219-S221.

Jirkowski, G.J., Wolff, C., Richter, S., 2015. Evolution of eumalacostracan development - new insights into loss and reacquisition of larval stages revealed by heterochrony analysis. EvoDevo 6, 4. DOI: 10.1186/2041-9139-6-4.

Kamps, D.M., 1978. The effect of temperature on the development time and brood size of Diaptomus pallidus Herrick. Hydrobiologia 61, 75-80.

Karimi-Malati, A., Fathipour, Y., Talebi, A.A., 2014. Development response of Spodoptera exigua to eight constant temperatures: linear and nonlinear modeling. J. Asia-Pac. Entomol. 17, 349-354.

Keppel, E.A., Scrosati, R.A., Courtenay, S.C., 2012. Ocean acidification decreases growth and development in American lobster (Homarus americanus) larvae. J. Northw. Atl. Fish. Sci. $44,61-66$.

Kiørboe, T., Sabatini, M., 1994. Reproductive and life cycle strategies in egg-carrying cyclopoid and free-spawning calanoid copepods. J. Plankton Res. 16, 1353-1366.

Kim, S.C., Song, J.-H., Kim, D.-S., 2008. Effect of temperature on the development and fecundity of the Cryptic Mealybug, Pseudococcus cryptus, in the laboratory. J. Asia-Pac. Entomol. 11, 149-153. 
982

983

984

985

986

987

988

989

990

991

992

993

994

995

996

997

998

999

1000

1001

1002

1003

Klein Bretetler, W.C.M., 1980. Continuous breeding of marine pelagic copepods in the presence of heterotrophic dinoflagellates. Mar. Ecol. Prog. Ser. 2, 229-233.

Klein Breteler W.C.M., Gonzalez, S.R., Schogt, N., 1995. Development of Pseudocalanus elongatus (Copepoda, Calanoida) cultured at different temperature and food conditions. Mar. Ecol. Prog. Ser. 119, 99-110.

Kuang X., Parajulee, M.N., Shi, P., Ge, F., Xue, F., 2012. Testing the rate isomorphy hypothesis using five statistical methods. Insect Sci. 19, 121-128.

Leandro, S.M., Queiroga, H., Rodríguez-Graña, L., Tiselius, P., 2006a. Temperature-dependent development and somatic growth in two allopatric populations of Acartia clausi (Copepoda: Calanoida). Mar. Ecol. Prog. Ser. 322, 189-207.

Leandro, S.M., Tiselius, P., Queiroga, H., 2006b. Growth and development of nauplii and copepodites of the estuarine copepod Acartia tonsa from southern Europe (Ria de Aveiro, Portugal) under saturating food conditions. Mar. Biol. 150, 121-129.

Lefebvre, F., Pasquerault, T., 2004. Temperature-dependent development of Ophyra aenescens (Wiedemann, 1830) and Ophyra capensis (Wiedemann, 1818) (Diptera, Muscidae). Forensic Sci. Int. 139, 75-79.

Li, D., 2002. The combined effects of temperature and diet on development and survival of a crab spider, Misumenops tricuspidatus (Fabricius) (Araneae: Thomisidae). J. Therm. Biol. 27, 83-93.

Lin, S., Shao, L., Hui, C., Sandhu, H.S., Fan, T., Zhang, L., Li, F., Ding, Y., Shi, P., 2018. The effect of temperature on the developmental rates of seedling emergence and leafunfolding in two dwarf bamboo species. Trees-Struct. Funct. 32, 751-763. 
MacKenzie, B.R., 1988. Assessment of temperature effects on interrelationships between stage durations, mortality, and growth in laboratory-reared Homarus americanus Milne Edwards larvae. J. Exp. Mar. Biol. Ecol. 116, 87-98.

Martin, J.W., Olesen, J., Høeg, J.T., 2014. Introduction. In: Martin, J.W., Olesen, J., Høeg, J.T. (Eds.), Atlas of Crustacean Larvae. Johns Hopkins University Press, Baltimore, MD, USA, pp. 1-7.

Mazerolle, M.J., 2016. AICcmodavg: Model selection and multimodel inference based on (Q)AIC(c). R Package Version 2.0-4. Available at: http://CRAN.Rproject.org/package=AICcmodavg .

Miller, C.B., 2008. Copepod growth in detail: pattern similarity to decapod larvae. ICES J. Mar. Sci. 65, 332-338.

Miller, C.B., Johnson, J.K., Heinle, D.R., 1977. Growth rates in the marine copepod genus Acartia. Limnol. Oceanogr. 22, 326-335.

Miller, C.B., Lynch, D.R., Carlotti, F., Gentleman, W., Lewis, C.V.W., 1998. Coupling of an individual-based population dynamic model of Calanus finmarchicus to a circulation model for the Georges Bank region. Fish. Oceanogr. 7, 219-234.

Niehaus, A.C., Angilletta, M.J., Jr., Sears, M.W., Franklin, C.E., Wilson, R.S., 2012. Predicting the physiological performance of ectotherms in fluctuating thermal environments. J. Exp. Biol. 215, 694-701.

Nietschke, B.S., Magarey, R.D., Borchert, D.M., Calvin, D.D., Jones, E., 2007. A developmental database to support insect phenology models. Crop Prot. 26, 1444-1448.

Nondillo, A., Redaelli, L.R., Botton, M., Pinent, S.M.J., Gitz, R., 2008. Exigências térmicas e estimativa do número de gerações anuais de Frankliniella occidentalis (Pergande) 
(Thysanoptera: Thripidae) em morangueiro [Thermal requirements and estimate of the annual number of generations of Frankliniella occidentalis (Pergande) (Thysanoptera: Thripidae) on strawberry crop]. Neotrop. Entomol. 37, 646-650.

de Oliveira, S.A., Souza, B., Auad, A.M., da Silva, D.M., Souza, L.S., Carvalho, C.A., 2009. Desenvolvimento e reprodução de Sipha flava (Forbes) (Hemiptera: Aphididae) em diferentes temperaturas. Neotrop. Entomol. 38, 311-316.

Oliphant, A., Hauton, C., Thatje, S., 2013. The implications of temperature-mediated plasticity in larval instar number for development within a marine invertebrate, the shrimp Palaemonetes varians. PLoS ONE 8(9), e75785.

Ouellet, P., Chabot, D., 2005. Rearing Pandalus borealis (Krøyer) larvae in the laboratory I. Development and growth at three temperatures. Mar. Biol. 147, 869-880.

Pakyari, H., Fathipour, Y., Enkegaard, A., 2011. Estimating development and temperature thresholds of Scholothrips longicornis (Thysanoptera: Thripidae) on eggs of two-spotted spider mite using linear and nonlinear models. J. Pest Sci. 84, 153-163.

Peterson, W.T., 2001. Patterns in stage duration and development among marine and freshwater calanoid and cyclopoid copepods: a review of rules, physiological constraints, and evolutionary significance. Hydrobiologia 453/454, 91-105.

Peterson, W.T., Painting, S.J., 1990. Developmental rates of the copepods Calanus australis and Calanoides carinatus in the laboratory, with a discussion of methods used for calculation of development time. J. Plankton. Res. 22, 283-293.

Picard, R., Cook, D., 1984. Cross-validation of regression models. J. Am. Stat. Assoc. 79, 575583. 
Pineda, J., Reyns, N., 2018. Larval transport in the coastal zone: biological and physical processes. In: Carrier, T.J., Reitzel, A.M., Heyland, A, (Eds.), Evolutionary Ecology of Marine Invertebrate Larvae. Oxford University Press, Oxford, UK, pp. 141-159.

Quinn, B.K., 2016. Extra and "intermediate" larval stages in decapod Crustacea: a review of physiological causes and ecological implications, with emphasis on lobsters, Homarus spp. In: Alvarado, V. (Ed.), Crustaceans: Physiological Characteristics, Evolution and Conservation Strategies. Nova Science Publishers, Inc., Hauppauge, NY, USA, pp. 19-80.

Quinn, B.K., 2017. A critical review of the use and performance of different function types for modeling temperature-dependent development of arthropod larvae. J. Therm. Biol. 63, $65-77$.

Quinn, B.K., Rochette, R., Ouellet, P., Sainte-Marie, B., 2013. Effect of temperature on development rate of larvae from cold-water American lobster (Homarus americanus). J. Crustac. Biol. 33, 527-536.

R Core Team (2014). R: A Language and Environment for Statistical Computing. R Foundation for Statistical Computing, Vienna, Austria.URL: http://www.R-project.org/.

Rebaudo, F., Rabhi, V.-B., 2018. Modeling temperature-dependent development rate and phenology in insects: review of major developments, challenges, and future directions. Entomol. Exp. Appl. In Press. DOI: 10.1111/eea.12693.

Reitzel, A.M., Miner, B.G., McEdward, L.R., 2004. Relationships between spawning date and larval development time for benthic marine invertebrates: a modeling approach. Mar. Ecol. Prog. Ser. 280, 13-23. 
1070

1071

1072

1073

1074

1075

1076

1077

1078

1079

1080

1081

1082

1083

1084

1085

1086

1087

1088

1089

1090

de Rivera, C.E., Hitchcock, N.G., Teck, S.J., Steves, B.P., Hines, A.H., Ruiz, G.M., 2007. Larval development rate predicts range expansion of an introduced crab. Mar. Biol. 150, 12751288.

Sandhu, H. S., Shi, P., Kuang, X., Xue, F., Ge, F., 2011. Applications of the bootstrap to insect physiology. Fla. Entomol. 94, 1036-1041.

Schneider, C.A., Rasband, W.S., Eliceiri, K.W., 2012. NIH Image to ImageJ: 25 years of image analysis. Nature Methods 9, 671-675.

Schoolfield, R.M., Sharpe, P.J.H., Magnuson, C.E., 1981. Non-linear regression of biological temperature-dependent rate models based on absolute reaction-rate theory. J. Theor. Biol. 88, 719-731.

Shi, P.,Ge, F., Men, X., 2010. How to compare the lower developmental thresholds. Environ. Entomol. 39, 2033-2038.

Shi, P., Wang, B., Ayres, M.P., Ge, F., Zhong, 661 L., Li, B., 2012. Influence of temperature on the northern distribution limits of Scirpophaga incertulas Walker (Lepidoptera: Pyralidae) in China. J. Therm. Biol. 37, 130-137.

Shi, P., Reddy, G.V.P., Chen, L., Ge, F., 2016. Comparison of thermal performance equations in describing temperature-dependent developmental rates of insects: (I) empirical models. Ann. Entomol. Soc. Am. 109, 211-215.

Shi, P., Fan, M., Reddy, G.V.P., 2017a. Comparison of thermal performance equations in describing temperature-dependent developmental rates of insects: (III) phenological applications. Ann. Entomol. Soc. Am. 110, 558-564. 
1091 Shi, P., Reddy, G.V.P., Chen, L., Ge, F., 2017b. Comparison of thermal performance equations in describing temperature-dependent developmental rates of insects: (II) two thermodynamic models. Ann. Entomol. Soc. Am. 110, 113-120.

1094

Thompson, B.M., 1982. Growth and development of Pseudocalanus elongatus and Calanus sp. in the laboratory. J. Mar. Biol. Assoc. UK 62, 359-372. 
1114 Table 1. The number of species' datasets (in parentheses) for which data on different

1115 developmental stages and/or phases were obtained. Stages written in italicized text are true

1116 larvae, present in taxa (crustaceans and holometabolous insects) that undergo metamorphic

1117 development only; taxa without larvae (arachnids and hemimetabolous insects) undergo direct or

1118 anamorphic development through juvenile instars (e.g., nymphs). Within each column, each row

1119 represents a different developmental phase (for some taxa, there is more than type of larval

1120 and/or juvenile phase). Stage ranges listed in square brackets were reported as combined

1121 durations in the indicated number of studies.

\begin{tabular}{|c|c|c|c|c|c|}
\hline \multicolumn{2}{|c|}{ Chelicerata: Arachnida } & \multicolumn{2}{|c|}{ Crustacea } & \multicolumn{2}{|c|}{ Hexapoda: Insecta } \\
\hline Acari & Aranea & Copepoda & Decapoda & "Hemimetabola"'a & Holometabola \\
\hline Egg (9) & $\operatorname{Egg}(0)$ & $\operatorname{Egg}(7)$ & $\operatorname{Egg}(0)$ & Egg (6) & Egg (16) \\
\hline \multirow[t]{4}{*}{$\begin{array}{l}\text { Juvenile: } \\
\text { "larva",b (8), } \\
\text { protonymph } \\
\text { (7), } \\
\text { tritonymph } \\
(2), \\
\text { deutonymph } \\
(5) ;[\text { total } \\
\text { juvenile }(2)]\end{array}$} & $\begin{array}{l}\text { Juvenile } \\
\text { instar: I } \\
(0), \text { II } \\
(1), \text { III } \\
(1), \text { IV } \\
(1), \text { V } \\
(1), \text { VI } \\
(1), \text { VII } \\
(1)\end{array}$ & $\begin{array}{l}\text { Nauplius: I } \\
\text { (3), II (3), III } \\
\text { (4), IV (4), } \\
\text { V (4), VI } \\
\text { (4); [I-VI } \\
(5)]\end{array}$ & $\begin{array}{l}\text { Nauplius: } \\
\text { [I-VI (1)] }\end{array}$ & $\begin{array}{l}\text { Nymphal instar: I } \\
(8), \text { II (8), III (6), } \\
\text { IV (4), V (2); [egg } \\
+ \text { instar I (1)] }\end{array}$ & $\begin{array}{l}\text { Larval instar: I } \\
(12), \text { II (12), III } \\
(12),[\text { II-III (1)], } \\
\text { IV }\left(9+1^{d}\right), V \\
(4), \text { VI (2) }\end{array}$ \\
\hline & & $\begin{array}{l}\text { Copepodite: } \\
\text { I (5), II (5), } \\
\text { III (5), IV } \\
(5), \text { V (5), I- } \\
\text { V (1) }\end{array}$ & $\begin{array}{l}\text { Protozoea: } \\
{[\text { I-III (1)] }}\end{array}$ & $\begin{array}{l}\text { Prepupa (1); } \\
{[\text { instar I-V + }} \\
\text { prepua (3)] }\end{array}$ & $\begin{array}{l}\text { Prepupa }(6) ; \\
\text { [egg + instar I- } \\
V+\text { prepupa } \\
(1)]\end{array}$ \\
\hline & & & $\begin{array}{l}\text { Zoea (or } \\
\text { mysis): I } \\
(17), \text { II (18), } \\
\text { III (15), [I- } \\
\text { III (1)], IV } \\
\left(8+1^{c}\right), \text { V } \\
(5), \text { VI (2), } \\
\text { VII (1), VIII } \\
(1), \text { IX (1) }\end{array}$ & $\begin{array}{l}\text { Pupa (2); [instar } \\
\text { II-V + prepupa }+ \\
\text { pupa (1)] }\end{array}$ & Pupa (18) \\
\hline & & & $\begin{array}{l}\text { Decapodid } \\
\text { (8) }\end{array}$ & $\begin{array}{l}\text { Pre-reproductive } \\
\text { (2) }\end{array}$ & \\
\hline
\end{tabular}

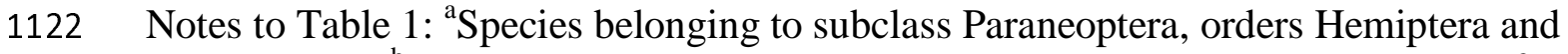

1123 Thysanoptera; ${ }^{\text {b}}$ The first juvenile instar of mites is called a "larva" by convention; ${ }^{c}$ For one 


\begin{tabular}{|c|c|}
\hline Model & Generalized linear model equation \\
\hline ICD & $\sin ^{-1} \sqrt{\operatorname{Prop}\left(S_{i}, T\right)}=\sin ^{-1} \sqrt{n^{-1}}=\sin ^{-1} \sqrt{\operatorname{Prop}\left(S_{1}\right)}$ \\
\hline EPD & $\sin ^{-1} \sqrt{\operatorname{Prop}\left(S_{i}, T\right)}=\sin ^{-1} \sqrt{\operatorname{Prop}\left(S_{1}\right)}+A S_{2}+B S_{3}+\cdots+X S_{n}$ \\
\hline VPD (Lin) & $\begin{array}{c}\sin ^{-1} \sqrt{\operatorname{Prop}\left(S_{i}, T\right)}=\sin ^{-1} \sqrt{\operatorname{Prop}\left(S_{1}\right)}+a_{1} T+A S_{2}+B S_{2} T+C S_{3}+D S_{3} T \\
+\cdots+X S_{n}+Y S_{n} T\end{array}$ \\
\hline $\begin{array}{l}\text { VPD } \\
\text { (Quad) }\end{array}$ & $\begin{array}{c}\sin ^{-1} \sqrt{\operatorname{Prop}\left(S_{i}, T\right)}=\sin ^{-1} \sqrt{\operatorname{Prop}\left(S_{1}\right)}+a_{1} T+b_{1} T^{2}+A S_{2}+B S_{2} T+C S_{2} T^{2} \\
+D S_{3}+E S_{3} T+F S_{3} T^{2}\end{array}$ \\
\hline & $+\cdots+X S_{n}+Y S_{n} T+Z S_{n} T^{2}$ \\
\hline
\end{tabular}

species, this stage was subdivided into 4 sub-stages (Zoea IVa-IVd); ${ }^{\mathrm{d}}$ For one species, this instar was divided into an active feeding sub-stage ("before turning purple") and an inactive prepupal sub-stage ("after turning purple"); see Supplementary Files 1-3 for more information.

Table 2. Generalized linear model (GLM) equations representing different modes of arthropod immature development (ICD = isochronal, EPD = equiproportional, and VPD (Lin) and VPD $($ Quad $)$ = 'variable proportional' development following a linear or quadratic form, respectively) tested on arcsine-square-root transformed developmental proportion data in this study. In these equations $\operatorname{Prop}\left(\mathrm{S}_{\mathrm{i}}, \mathrm{T}\right)=$ the proportion of total development spent in stage ' $\mathrm{i}$ ' at temperature ' $\mathrm{T}$ ' (in ${ }^{\circ} \mathrm{C}$ ), $\mathrm{n}=$ the total number of stages, $\mathrm{S}_{2}, \mathrm{~S}_{3}, \ldots, \mathrm{S}_{\mathrm{n}}$ are logical variables with values of 1 if $\mathrm{S}_{\mathrm{i}}$ is equal to the number of a given stage $(\mathrm{S})$ or 0 otherwise, $\mathrm{A}-\mathrm{F}$ and $\mathrm{X}-\mathrm{Z}$ are fitted coefficients multiplied by the stage $(\mathrm{S})$ and temperature $(\mathrm{T})$ variables or their interactions, the intercept is the transformed proportion of development spent in the first developmental stage $\left(S_{1}\right)$, and $a_{1}$ and $b_{1}$ are fitted coefficients representing the effects of $\mathrm{T}$ and $\mathrm{T}^{2}$, respectively, on developmental proportions in general and the proportion of development spent in $S_{1}$ specifically. 


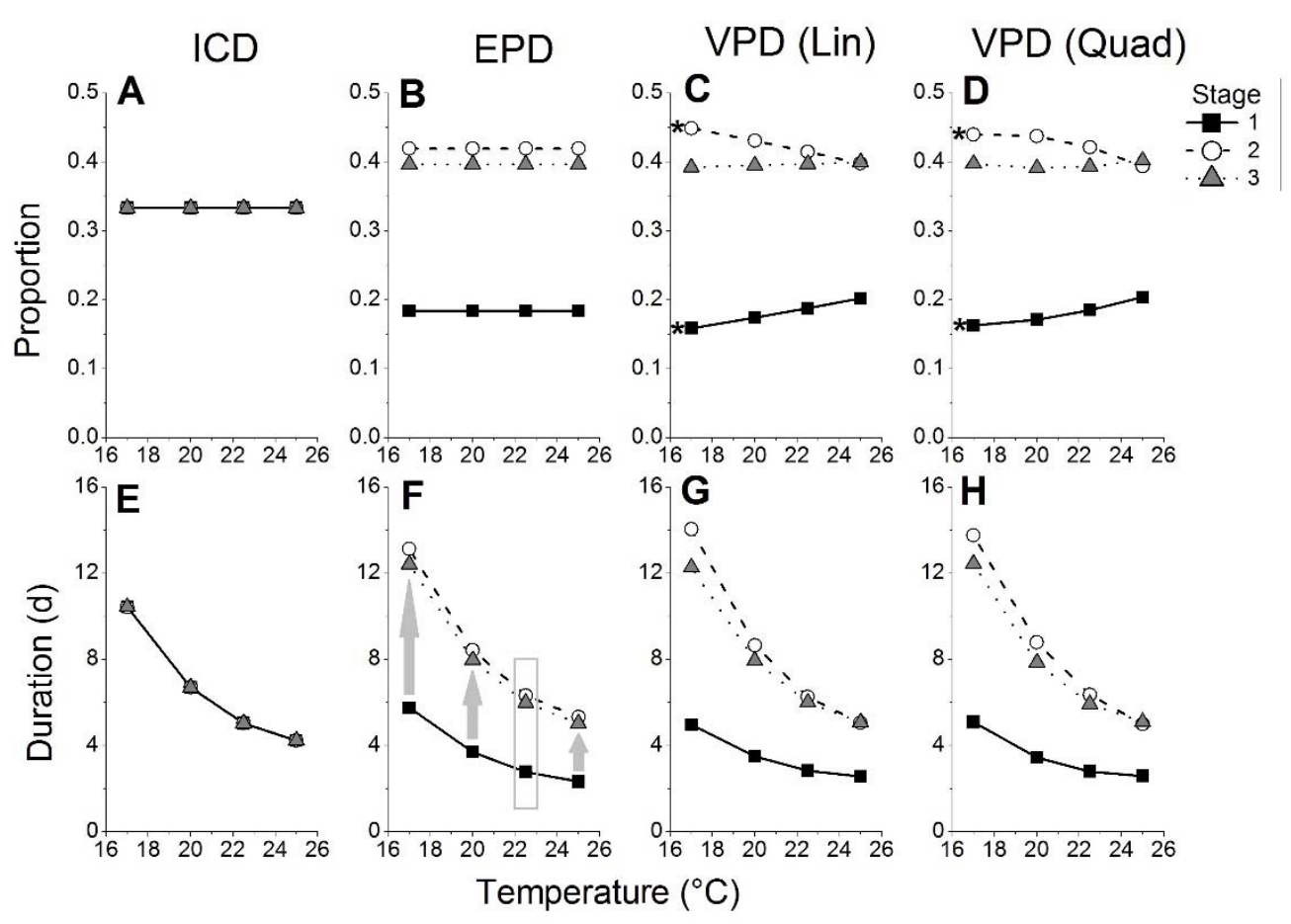

1141 Figure 1. Examples of isochronal (ICD), equiproportional (EPD), and linear (Lin) and quadratic

1142 (Quad) forms of 'variable proportional' development (VPD) of a hypothetical arthropod with

1143 three immature stages (signified by different symbols and lines). Plots show the proportion of

1144 total development (A-D) and development time (in days (d), E-H) spent in each stage at each of

1145 four temperatures (in $\left.{ }^{\circ} \mathrm{C}\right)$. In $\operatorname{ICD}(\mathrm{A}, \mathrm{E})$ values for all stages are identical and overlap, in EPD

$1146(\mathrm{~B}, \mathrm{~F})$ values are the same across temperatures but differ among stages, and in VPD $(\mathrm{C}, \mathrm{D}, \mathrm{G}, \mathrm{H})$

1147 values differ among temperatures and stages. In $(\mathrm{F})$, the use of EPD to predict the durations of

1148 later stages (2 and 3) at temperatures of 17,20 , and $25^{\circ} \mathrm{C}$ based on observed durations of stage 1

1149 at these temperatures and observed proportions of development spent in all three stages at $22.5^{\circ} \mathrm{C}$

1150 (gray box) is illustrated. In (C) and (D), 'mixed' development is illustrated, in which proportions

1151 spent in stages 1 and 2 are affected by temperature (the '*' indicates a significant effect of

1152 temperature) but those in stage 3 are not. 


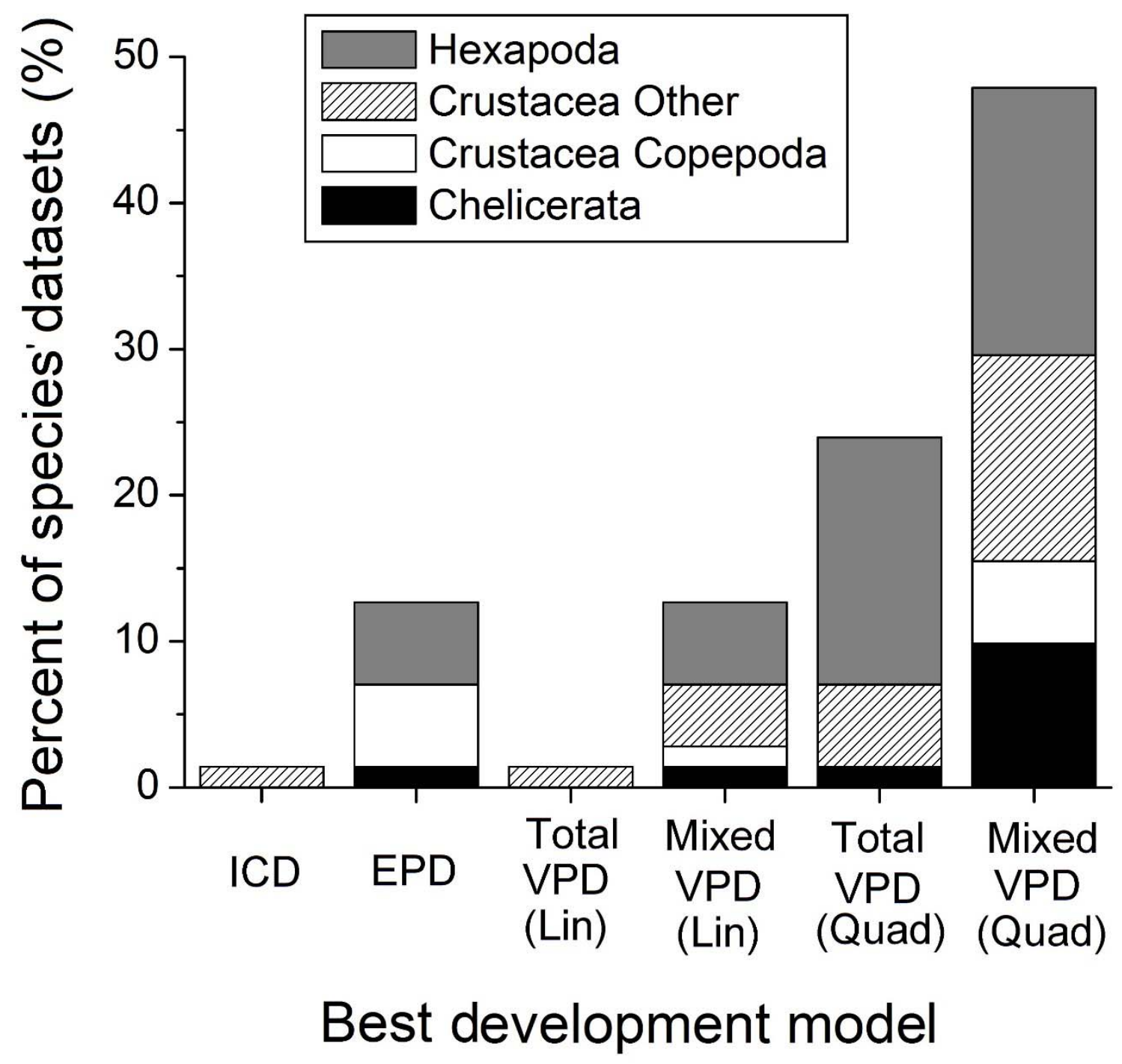

1154 Figure 2. The percentage $(\%)$ of all species' datasets (total $=71)$ for which each model of

1155 development was found to be the best (based on $\mathrm{AIC}_{\mathrm{C}}$ ranking) in different arthropod groups.

$1156 \mathrm{ICD}=$ isochronal development; $\mathrm{EPD}=$ equiproportional development; VPD = variable

1157 proportional development, which could take either a linear (Lin) or quadratic (Quad) form, and

1158 be 'total' (all stages' proportions significantly affected by temperature) or 'mixed' (one or more

1159 stages' proportions significantly affected by temperature, but not all stages). 


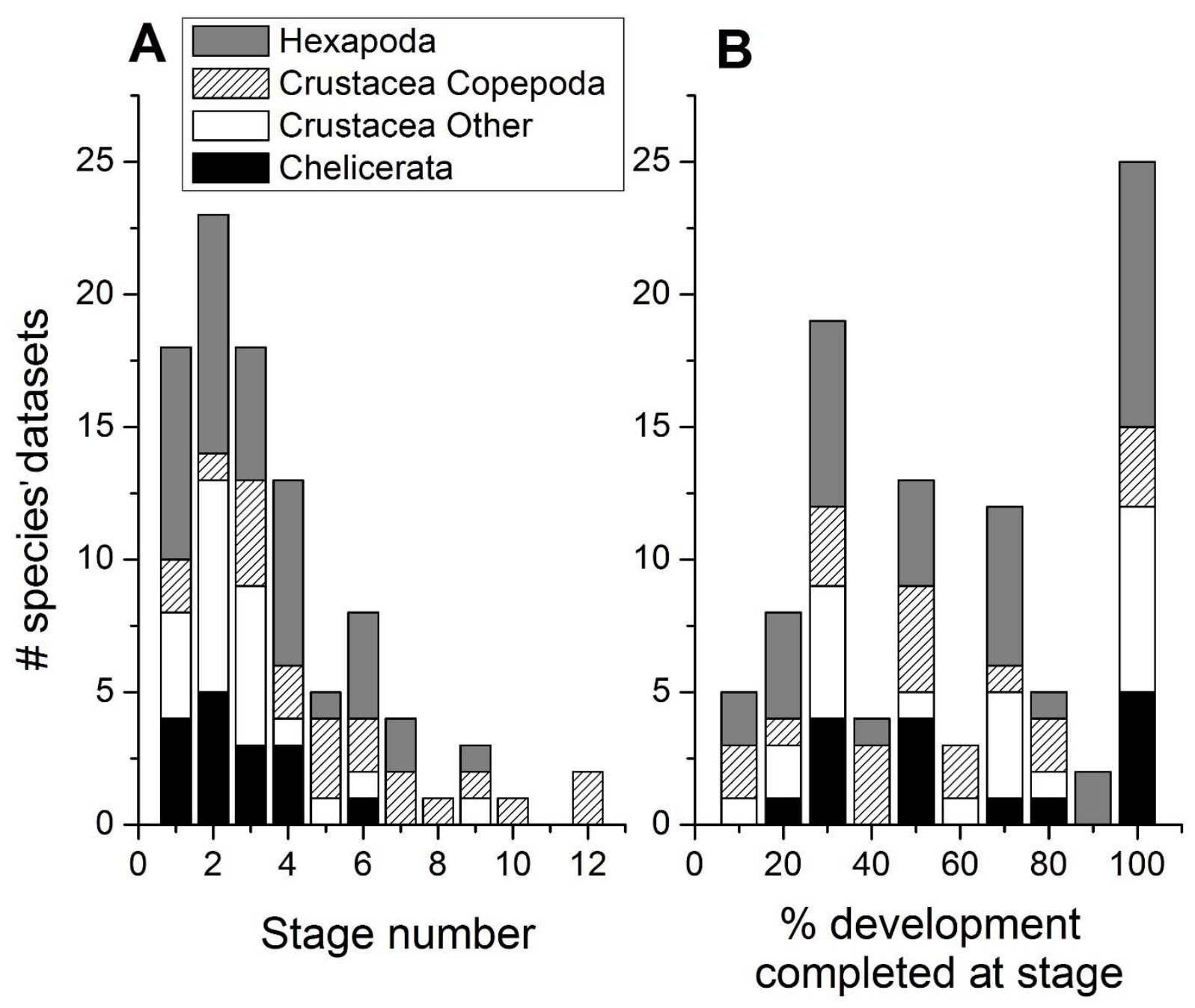

1162 Figure 3. The number of species' datasets with a mixed VPD type of development in which the

1163 developmental proportions for stages with different numbers (A, stages numbered from earliest

1164 to latest) or at which different percentages $(\%)$ of development were completed (B, calculated by

1165 dividing the stage number in A by the total number of stages in a species) were significantly

1166 affected by temperature. Data are divided up according to different arthropod groups. 


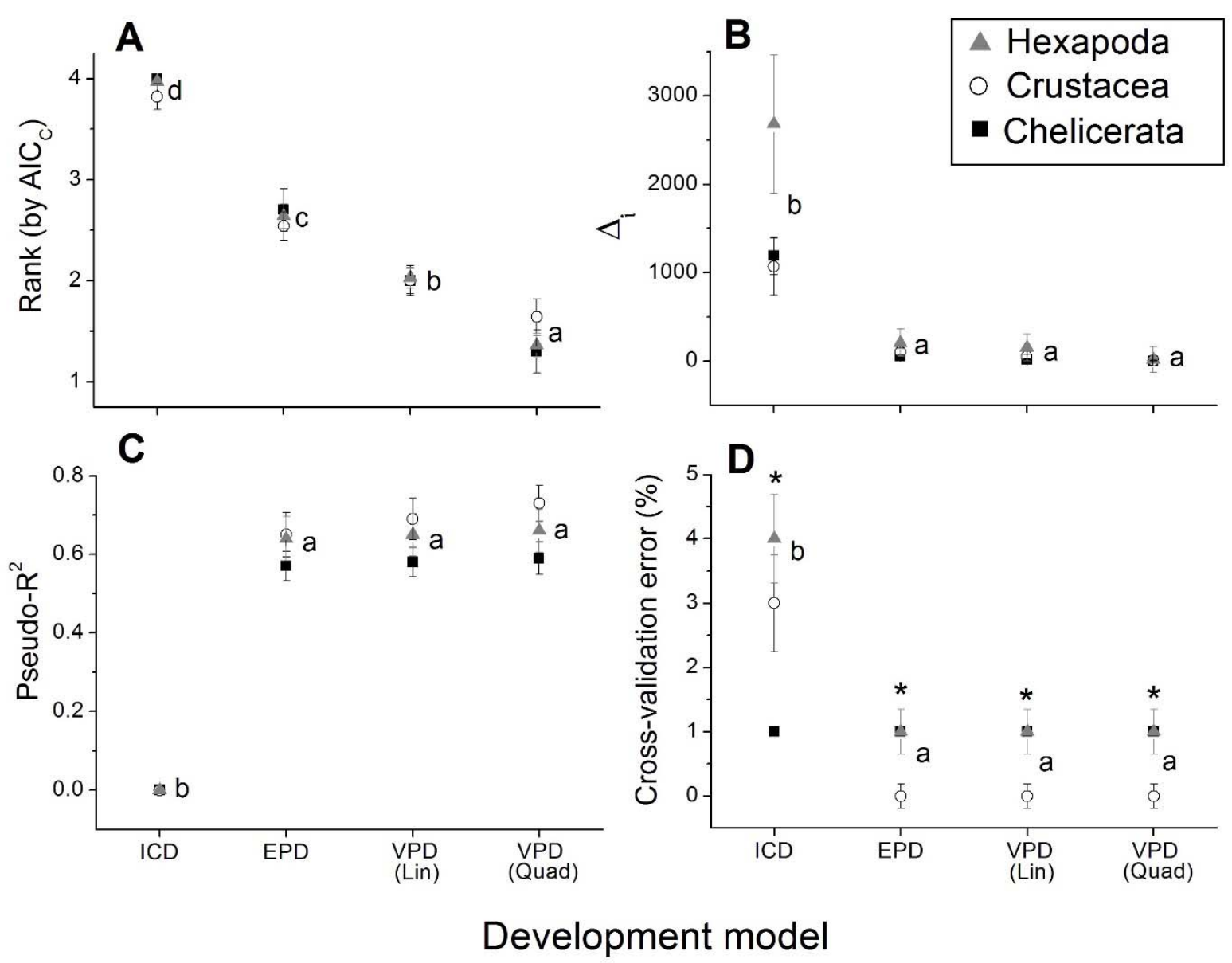

1168 Figure 4. Performance of the different development models tested in this study (isochronal

1169 (ICD), equiproportional (EPD), and linear (Lin) and quadratic (Quad) forms of variable

1170 proportional (VPD) development), assessed based on each model's (A) ranking based on $\mathrm{AIC}_{\mathrm{C}}$

1171 ( 1 = best, 4 = worst $),(B)$ model $\Delta_{\mathrm{i}}$ based on $\mathrm{AIC}_{\mathrm{C}}$ values, $(\mathrm{C})$ pseudo-R ${ }^{2}$, and $(\mathrm{D})$ cross-

1172 validation error (\%) when tested on data for each arthropod species. Mean \pm SE values of each

1173 performance metric are plotted for each model and arthropod subphylum (chelicerates $=$ black

1174 squares, crustaceans $=$ white circles, and hexapods = gray triangles). Different lowercase letters

1175 to the right of the cluster of values for each model indicate models whose performance metrics

1176 varied significantly (Tukey's HSD test, $\mathrm{p} \leq 0.05$ ), while an asterisk ('*') above these points

1177 indicates that performance differed significantly among subphyla (ANOVA, $\mathrm{p} \leq 0.05$ ). 

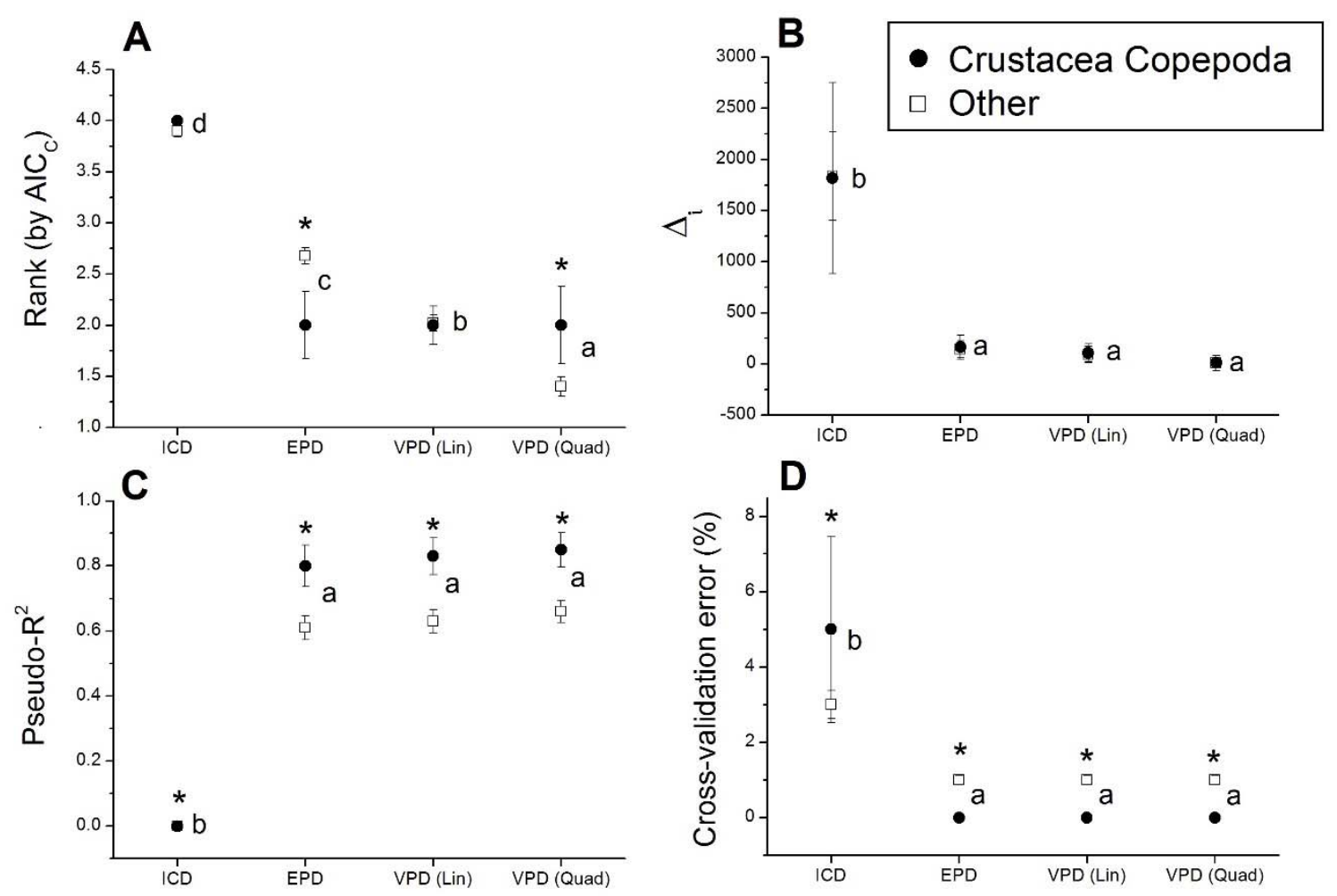

Development model

1179 Figure 5. Performance of the different development models tested in this study (isochronal

1180 (ICD), equiproportional (EPD), and linear (Lin) and quadratic (Quad) forms of variable

1181 proportional (VPD) development), assessed based on each model's (A) ranking based on AIC $_{\mathrm{C}}$

1182 ( 1 = best, 4 = worst $),(B)$ model $\Delta_{\mathrm{i}}$ based on $\mathrm{AIC}_{\mathrm{C}}$ values, $(\mathrm{C})$ pseudo- $\mathrm{R}^{2}$, and $(\mathrm{D})$ cross-

1183 validation error (\%) when tested on data for copepod crustacean species (black circles) compared

1184 with those of all other arthropod taxa (white squares) species. Mean \pm SE values of each

1185 performance metric are plotted for each model and group. Different lowercase letters to the right

1186 of the cluster of values for each model indicate models whose performance metrics varied

1187 significantly (Tukey’s HSD test, $\mathrm{p} \leq 0.05$ ), while an asterisk ('*’) above these points indicates

1188 that performance differed significantly between copepod and non-copepod species (ANOVA, $\mathrm{p} \leq$ $11890.05)$. 


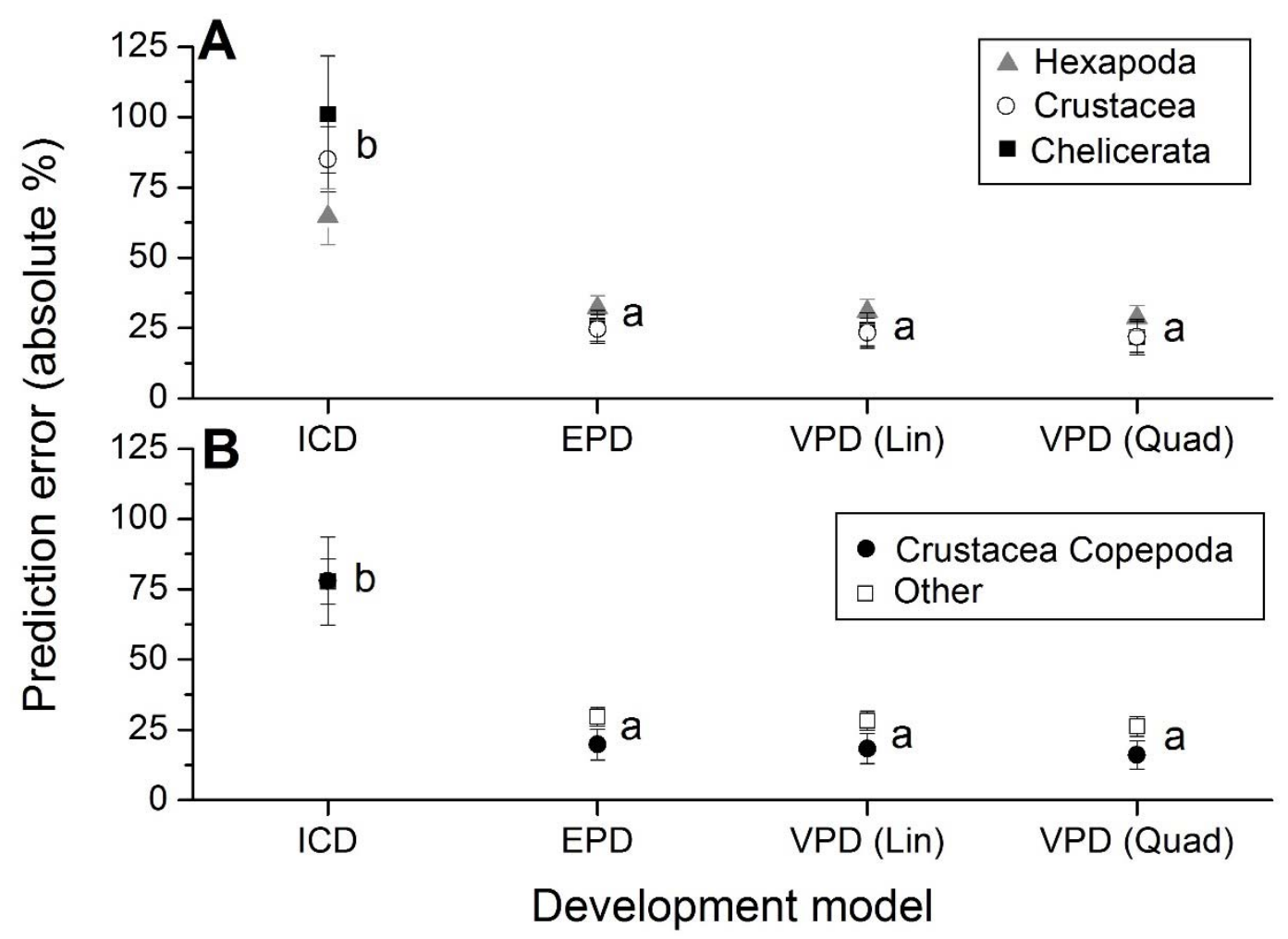

1191 Figure 6. Prediction errors of the different development models tested in this study (isochronal

1192 (ICD), equiproportional (EPD), and linear (Lin) and quadratic (Quad) forms of variable

1193 proportional (VPD) development). An average absolute percent (\%) error was calculated for

1194 each species' dataset by comparing durations predicted based on each model for all later stages

1195 based on the duration of the first stage (see section 2.5 for details) to the actual observed

1196 durations for these stages in original studies. Mean \pm SE values of prediction error calculated

1197 across species are plotted for each model and (A) arthropod subphylum (chelicerates $=$ black

1198 squares, crustaceans $=$ white circles, and hexapods $=$ gray triangles $)$ or $(B)$ for copepod

1199 crustaceans (black circles) and all other arthropod taxa (white squares). Different lowercase

1200 letters to the right of the cluster of values for each model indicate models whose prediction errors

1201 differed significantly (Tukey's HSD test, $\mathrm{p} \leq 0.05$ ); prediction errors did not differ significantly

1202 among subphyla or between copepod and non-copepod species (ANOVA, p > 0.05). 
Electronic Supplementary Materials:

Supplementary File 1. Contains Tables S1 and S2, along with their associated reference lists.

Table S1. Species of copepods (subphylum Crustacea: class Hexanauplia: subclass Copepoda:

1208 infraclass Neocopepoda) that previous studies concluded or suggested had either ICD or EPD.

1209 The information in this table was obtained through the literature searches (Web of Science and

1210 Google Scholar) discussed in the Introduction (section 1) of the main text.

1211

Table S2. Arthropod species for which datasets were obtained from previously published studies

1213 and used in analyses within this one.

1215 Supplementary File 2. Contains the datasets extracted for each species from each study ('Input Data'), an R code ('EPD tests code') written by the author to test each dataset for ICD, EPD, and

1217 linear and quadratic forms of VPD and produce $\mathrm{AIC}_{\mathrm{C}}$ values, cross-validation errors, and

1218 summary output for each of these development models, and the R output of analyses performed

1219 with this code on each species' dataset ('Output Data').

1221 Supplementary File 3. Contains Tables S3 and S4.

1223 Table S3. Summary of performance metrics calculated for each development model [ICD, EPD,

1224 VPD (Lin), and VPD (Quad)] for each species' dataset tested, including model AIC $\mathrm{C}_{\mathrm{C}}, \Delta_{\mathrm{i}}$, rank

1225 based on $\mathrm{AIC}_{\mathrm{C}}(1-4)$, cross-validation error, pseudo- $\mathrm{R}^{2}$, and mean raw (in d) and percent (\%) 
1226 absolute prediction errors calculated for each species' dataset. Whether conditions for concluding

1227 ICD or EPD were met by the data is also outlined. Whether original studies reported full

1228 development times and if each species had anamorphic or metamorphic development is also

1229 listed. The number of developmental stages whose proportions were significantly affected by

1230 temperature or not is also listed, as well as the proportion of stages with significant temperature

1231 effects, and thus whether or not the species had mixed development. The studies cited in this

1232 table are provided with Table S2 in Supplementary File 1.

1233

1234 Table S4. The proportions of total development spent by each of the species examined in this

1235 study in each of their immature developmental stages, as predicted based on the parameters of

1236 development models fit to them using GLMs in the present study. For all equations, the predicted

1237 proportions were back-transformed from arcsine-square-roots. Equations are included as Excel

1238 formulae, and those for VPD models are linked to values in the first column representing

1239 temperature (set to an arbitrary value of $15^{\circ} \mathrm{C}$ in this file). Whether the developmental proportion

1240 of each stage was significantly affected by temperature is also indicated $(1=$ affected, $0=$ not

1241 affected) in the columns to the right of each VPD model's column. Whether each developmental

1242 stage was feeding or non-feeding is also listed. The studies cited in this table are provided with

1243 Table S2 in Supplementary File 1. 